\title{
THE EFFECT OF BRCA GENE TESTING ON FAMILY RELATIONSHIPS: A THEMATIC ANALYSIS OF QUALITATIVE INTERVIEWS
}

\author{
by \\ Heather Ann Douglas \\ B.Sc.H., Queen’s University, Canada, 2004 \\ M.Sc., Queen’s University, Canada, 2006
}

Submitted to the Graduate Faculty of

The Graduate School of Public Health in partial fulfillment

of the requirements for the degree of

Master of Science

University of Pittsburgh 
UNIVERSITY OF PITTSBURGH

Graduate School of Public Health

This thesis was presented

by

Heather Ann Douglas

It was defended on

March 26, 2008

and approved by

Co-Thesis Director: Robin E. Grubs, PhD, CGC, Assistant Professor, Co-Director of the Genetic Counseling Program, Department of Human Genetics, Graduate School of Public Health, University of Pittsburgh

Co-Thesis Director: Rebekah J. Hamilton, MSN, PhD, Assistant Professor, Department of Health Promotion and Development, School of Nursing, University of Pittsburgh

Elizabeth A. Gettig, MS, CGC, Associate Professor, Co-Director of the Genetic Counseling Program, Department of Human Genetics, Graduate School of Public Health, University of Pittsburgh

Darcy L. Thull, MS, CGC, Cancer Genetic Counselor, Cancer

Genetics Program, University of Pittsburgh Cancer Institute 
Copyright (C) by Heather Ann Douglas 2008 


\title{
THE EFFECT OF BRCA GENE TESTING ON FAMILY RELATIONSHIPS: A THEMATIC ANALYSIS OF QUALITATIVE INTERVIEWS
}

\author{
Heather Ann Douglas, M.S. \\ University of Pittsburgh, 2008
}

Individuals with a personal or family history of cancer can pursue testing for mutations in BRCA1 and BRCA2, breast and ovarian cancer susceptibility genes, in order to help them make decisions about cancer risk-reducing surgeries and other management options. However, this genetic testing can also have emotional consequences, not only for the tested individual but also for his or her relatives since testing can provide risk information for them as well. Thus, this study investigated the impact of BRCA testing on family dynamics and family relationships. A qualitative research design was employed, in which a secondary analysis was conducted on interview transcripts. In the initial study, two open-ended, tape-recorded interviews were performed using grounded theory methodology with each of 12 participants approximately three years apart. All participants had tested positive for a mutation in either BRCA1 or BRCA2. Thematic analysis of interview transcripts was conducted in the current secondary analysis to characterize family relationships after BRCA testing. Three main themes were identified: 1. That the first in the family to have testing or seek genetic counseling takes on a special family role that can be difficult for them; 2. That discussions in the family, especially those associated with BRCA testing, often change after genetic testing; and 3. That individuals may feel more or less connected to certain family members after genetic testing has occurred in the family. These changes in family dynamics seem to depend on the family history of cancer, prior relationships within the family, emotional coping strategies of relatives, value placed on particular 
communication patterns, and sharing or not sharing the family's BRCA mutation. The results of this study highlight the profound changes in family life that can occur after BRCA testing. Health professionals can use the insight they gain from this study in their management of patients considering BRCA testing. This work also has public health relevance since it describes how genetic testing for susceptibility to a common disease can influence family dynamics. Such an understanding will be important as the genetic basis of common disease becomes better understood and tests for additional susceptibility genes become available. 
TABLE OF CONTENTS

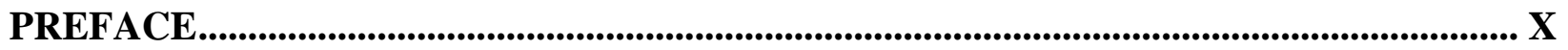

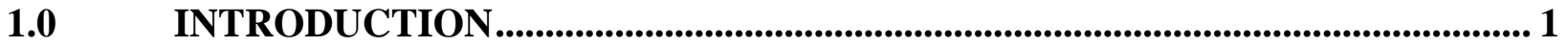

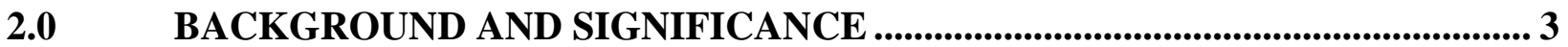

2.1 HEREDITARY BREAST/OVARIAN CANCER (HBOC) AND BRCA

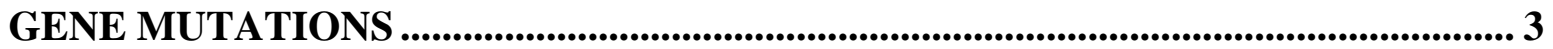

2.2 RISK PERCEPTION AND FAMILY RELATIONSHIPS IN THE CONTEXT OF HBOC FAMILY HISTORY ............................................................... 5

2.2.1 Perception of cancer risk in the context of HBOC family experience ..... 6 2.3 DECISIONS ABOUT UPTAKE OF GENETIC TESTING IN THE

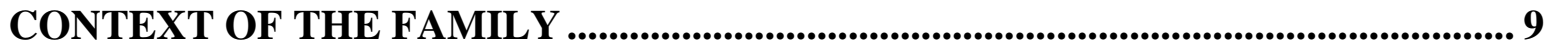

$2.4 \quad$ POST-TESTING REACTIONS OF THE TESTED INDIVIDUAL.............. 10

2.5 DISCLOSURE OF THE TEST RESULT TO FAMILY MEMBERS .......... 12

2.5.1 What are the reasons individuals give for wanting to disclose their genetic information to their relatives? ................................................................................... 13

2.5.1.1 Factors that have been found to increase the likelihood of disclosure .14

2.5.2 Barriers or deterrents to disclosing information to relatives..................... 15

2.5.3 Who are chosen as recipients of results? ....................................................... 17 
2.5.4 The disclosure process .................................................................................... 18

2.5.4.1 When and how does the disclosure happen? ....................................... 18

2.5.4.2 What information is disclosed? ............................................................. 20

2.5.5 How do the tellers feel about making the disclosure? ................................. 21

2.6 REACTIONS OF FAMILY MEMBERS TO THE DISCLOSURE AND

EFFECTS ON FAMILY RELATIONSHIPS ......................................................................... 22

2.6.1 How do families talk about having a BRCA mutation?.............................. 25

2.7 METHODOLOGY OF THE STUDIES OUTLINED ABOVE....................... 26

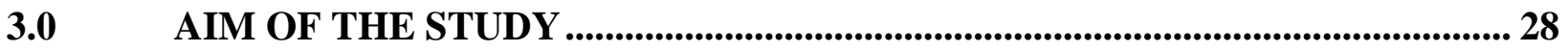

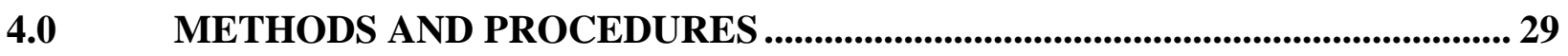

4.1.1 Interviews with research participants............................................................... 29

4.1.2 Participant recruitment....................................................................................... 30

4.1.3 Transcription....................................................................................................... 30

4.1.4 Thematic analysis as the method of secondary analysis............................. 31

4.1.4.1 Becoming familiar with data and background literature ................. 32

4.1.4.2 Generating initial codes............................................................................... 33

4.1.4.3 Memo writing ................................................................................................. 36

4.1.4.4 Identifying and characterizing themes ................................................. 36

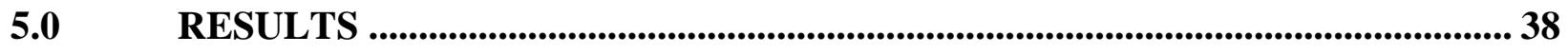

5.1 CHARACTERIZATION OF THE SAMPLE.................................................... 38

$5.2 \quad$ THEMES IDENTIFIED IN THE ANALYSIS .................................................... 38

5.2.1 Theme \# 1: New or changed family roles for the index case..................... 39

5.2.1.1 Obligation to inform family members .................................................. 39 
5.2.1.2 Acting on the responsibility to bring news to the family can be burdensome for the index case 40

5.2.1.3 Index case as role model........................................................................ 41

5.2.2 Theme \# 2: Genetic testing affects discussions in the family .................. 43

5.2.2.1 Testing facilitates conversations in the family ..................................... 43

5.2.2.2 Disapproval of topic during family discussion ...................................... 45

5.2.2.3 Open communication with family .............................................................. 48

5.2.2.4 No or few perceived changes, or did not mention it .......................... 50

5.2.3 Theme \# 3: Feeling more or less connected to family members .............50

5.2.3.1 Feeling a special connection with fellow mutation carriers .............. 50

5.2.3.2 Feeling left out if not sharing the family mutation ............................ 51

5.2.3.3 Feeling isolated or less connected if not receiving wanted family support.................................................................................................................................. 53

5.2.3.4 Genetic counseling process as a catalyst for initiating new relationships with relatives ................................................................................. 54

5.2.4 How are these three main themes connected?............................................ 55

5.2.5 Changes in family relationships over three years - first and second

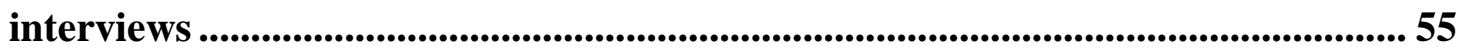

5.2.6 Other themes identified in the analysis........................................................... 56

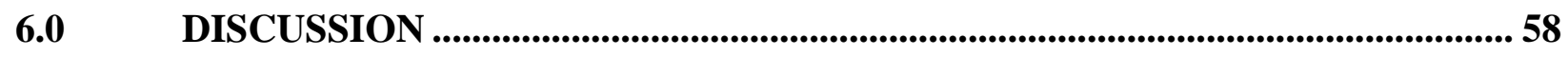

6.1 STUDY FINDINGS IN THE CONTEXT OF PREVIOUS WORK .............. 59

6.1.1 Theme \# 1: New or changed family roles as the index case ...................... 59

6.1.2 Theme \# 2: Genetic testing affects discussions in the family .................... 61 
6.1.3 Theme \# 3: Feeling more or less connected to family members .............. 62

IMPLICATIONS FOR GENETICS PROFESSIONALS......................... 63

6.3 IMPLICATIONS FOR PRIMARY CARE PROVIDERS ........................... 65

6.4 STUDY LIMITATIONS AND FUTURE RESEARCH ........................... 66

6.4.1 Recruitment and selection bias ..............................................................66

6.4.2 Grounded theory and interview methodology ....................................6 67

APPENDIX A INSTITUTIONAL REVIEW BOARD APPROVAL LETTER ................... 69

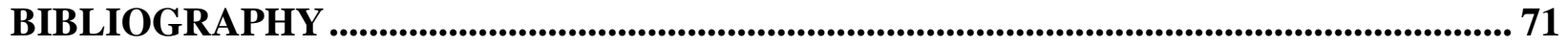




\section{PREFACE}

First and foremost, I would like to acknowledge all of the participants in this study for sharing their experiences so openly. These individuals were truly an inspiration to me and have greatly enhanced both my professional development and my personal maturation.

I would like to also acknowledge my thesis committee for their insight and direction, as well as my classmates for providing a listening ear for my enthusiasm with this project. As well, I'd like to thank the Department of Human Genetics at the University of Pittsburgh for providing me with QSR’s Nudist Vivo program for my analysis.

The preliminary interviews were supported by a research grant to Dr. Rebekah J. Hamilton from Sigma Theta Tau International. 


\subsection{INTRODUCTION}

In the 1990s, the discovery of the BRCA genes offered an explanation for the clustering of ovarian cancer and early onset breast cancer in some families. In these families, it was found that individuals who inherited a mutated copy of a BRCA gene had a lifetime risk of cancer much higher than that of the general population, while those who did not inherit a gene mutation had no elevated risk (Ford et al., 1994; The Breast Cancer Linkage Consortium, 1999).

Next came the opportunity for members of kindreds suspected to have a BRCA mutation to undergo genetic testing to detect a mutation. Individuals found to have a mutation would then know that cancer was likely in their future and could choose surgeries, like bilateral mastectomy or oophorectomy, to reduce their risk or could undergo frequent screening in attempt to detect cancer in early stages (NCCN Clinical Practice Guidelines). Individuals for whom no mutation was detected could be assured that they did not have an increased chance of cancer, so long as testing had confirmed that their family members with cancer did carry an identifiable BRCA mutation (NCCN Clinical Practice Guidelines).

Since early on in the gene discovery process, it had been recognized that this type of testing has the potential for serious psychological consequences (Bredart et al., 1998). To address this, typically BRCA testing is preceded by genetic counseling that includes a discussion of such consequences. Also, several studies have investigated the psychosocial effects of BRCA testing. However, very few have focused on how BRCA testing can impact the emotional 
relationships among family members. This is of concern since BRCA testing can provide cancer risk information not only for the tested individual but also for their relatives.

Thus, the goal of this study was to investigate how genetic testing for BRCA impacts family dynamics and the relationships between family members. To fulfill this goal, a qualitative thematic analysis was undertaken, in which interviews with individuals who had $B R C A$ testing were analyzed. Themes relating to the research goal were identified and will be presented and discussed in this paper. 


\subsection{BACKGROUND AND SIGNIFICANCE}

\subsection{HEREDITARY BREAST/OVARIAN CANCER (HBOC) AND BRCA GENE MUTATIONS}

It has long been suspected that the breast and ovarian cancer in some families has a hereditary basis (see Lynch et al. (1979) for a description of various hereditary cancer syndromes and their management recommendations over 25 years ago). The breast cancer in these families commonly occurs before menopause, often in close relatives and in several generations of the family (Thull and Vogel, 2004). These families also sometimes include individuals diagnosed with ovarian cancer, bilateral breast cancer, or both breast and ovarian cancer, as well as men diagnosed with breast cancer (Thull and Vogel, 2004). Cancer risk in these kindreds thus far outweighs that of the general population.

In the mid-1990s, the discovery of two genes, BRCA1 and BRCA2 (i.e. BRCA1/2 or BRCA for simplicity), provided an explanation for the hereditary nature of the cancer for many of these families. Women carrying a mutation in BRCA1 or BRCA2 have a $50-87 \%$ risk of developing breast cancer by age 70 (Domchek et al., 2003; Ford et al., 1998), up to a 27-44\% risk of developing ovarian cancer (Domchek et al., 2003; Ford et al., 1998), and an elevated risk of a second cancer (Berliner et al., 2007). They also have smaller risks for other types of cancer (Thull and Vogel, 2004). Male mutation carriers have a 20-30\% risk of prostate cancer (The 
Breast Cancer Linkage Consortium, 1999), a 5-10\% risk of breast cancer (Brose et al., 2002), and smaller risks for other types of cancer (Thull and Vogel, 2004). The elevated cancer susceptibility has an autosomal dominant mode of inheritance, meaning that both men and women can carry the BRCA mutation and both have a $50 \%$ chance of passing on the mutation to each of their offspring, whether it be a son or a daughter. The cancer risks and inheritance pattern explain why there is usually a cancer history in most generations of the family, with females more likely to be affected than males.

Testing for mutations in BRCA1 and BRCA2 is available and has a sensitivity of approximately 85\% (Myriad Genetics). Typically, the best family member to test first is one who has had a cancer diagnosis (especially breast cancer at a young age or ovarian cancer), since she is the most likely to have a detectable mutation if one is present. If a mutation is not found, the result is said to be 'inconclusive' since a mutation could still be present but undetected. If a mutation is found in the first tested individual in the family, it is said to be a 'conclusive' and 'positive' result, and at-risk family members can be tested for that specific mutation. Family members can either receive a conclusive positive result, when they are found to have the mutation, or a conclusive negative result, when they are not found to have the mutation.

Female mutation carriers are offered (NCCN Clinical Practice Guidelines):

1. Aggressive screening including breast imaging and ovarian screening, to detect cancer in early stages,

2. Medications such as Tamoxifen, Raloxifene, and oral contraceptives, to reduce the risk of cancer,

3. Surgeries such as bilateral mastectomy and salpingo-oophorectomy to reduce the risk of cancer, and 
4. Screening for other types of cancer as indicated by the family history. Male mutation carriers are offered (NCCN Clinical Practice Guidelines):

1. Breast exams and mammography if deemed necessary,

2. Early prostate screening, and

3. Screening for other types of cancer as indicated by the family history.

It is estimated that 1 in 800 people in the general population carry a BRCA mutation (Strewing et al., 1997). However, this rate varies significantly among ethnic groups. One notable group is the Ashkenazi Jewish population, in which the estimated carrier frequency is 1 in 40 individuals (Tonin et al., 1996).

\subsection{RISK PERCEPTION AND FAMILY RELATIONSHIPS IN THE CONTEXT OF HBOC FAMILY HISTORY}

Individuals considering genetic testing for a $B R C A$ mutation have often had their lives colored by cancer. Whether or not they themselves have been diagnosed, many have watched their loved ones undergo difficult treatments or die from the disease. Accordingly, these individuals can carry a heavy emotional burden related to their family's cancer history (Foster et al., 2002). Additionally, coping mechanisms and relationships in adulthood may be shaped by past experiences, such as having to care for a sick family member or losing a parent to cancer during the formative childhood or teenage years (Foster et al., 2002, Kenen et al., 2003a). Thus, it is important to consider how a strong family history of cancer could influence the perceptions and decision-making of women considering BRCA testing. 


\subsubsection{Perception of cancer risk in the context of HBOC family experience}

To date, most research about risk perception has been performed for women due to the greater cancer risks in female family members. The findings will be reviewed here.

Generally, women in families with a strong cancer history either seem to have 'always known' that cancer runs in the family, or have gradually realized this as more and more family members were diagnosed (Forrest et al., 2003). Some women seem to have come to this realization by comparing their families to 'the norm' and reasoning that the excess number of cancer diagnoses compared to a normal family meant that there was something 'in the family' (Foster et al., 2002). Women from a family with several generations known to have had cancer generally find it easier to understand where the cancer comes from than women from a family in which the known cancer cases are in the current generation only (Foster et al., 2002). Usually, girls or women who have a strong family history of breast and/or ovarian cancer are aware that they could follow the family pattern and get cancer as well (Kenen et al., 2003a; Hallowell, 1999; Forrest et al., 2003; Foster et al., 2002; Kenen et al., 2003b; Raveis and Pretter, 2005).

However, their perceptions of their own risk are subject to influence by the 'stories' about the cancer in the family (Kenen et al., 2003b). These stories seem to pass throughout the generations, becoming legacies whose content becomes ingrained in every new generation (Werner-Lin 2007) and is used to determine the risk of cancer for each individual in the family (Werner-Lin, 2007). Many of these stories are based on misconceptions, misunderstandings or secrets (Kenen et al., 2003b). For example, several studies have noted that resemblance to a relative, physically or behaviorally, is sometimes used by these families to predict whether or not an individual will get cancer (Blandy et al., 2003; Werner-Lin, 2007). For instance, one research participant in the Blandy et al. study (2003) stated, "In my mother’s family, all small girls with 
curly hair develop a cancer, while the others with straight hair do not.” This misconception may stem from the general public's perception of inheritance as a collection of characteristics that is joined together and passed from generation to generation (Kenen et al., 2003b). Other family stories may involve missing elements that were accidentally overlooked by relatives (Kenen et al., 2003b) or that were deliberately hidden, often generations ago, due to the stigma associated with cancer at that time (Kenen et al., 2003b).

The perceived saliency of personal risk seems to be higher among women whose relatives did not survive their cancer, women who had a mother or sister with cancer, or women who have a relative recently diagnosed (Kenen et al., 2003a; Foster et al., 2002). Raveis and Pretter (2005) investigated these trends and found that adult care-giving daughters learning of their mother's breast cancer diagnosis undergo a realization of their personal vulnerability that can result in an intense emotional crisis, even though they may have already suspected a heritable component to the cancer in their family.

Saliency of personal risk can also wax or wane with breast or ovarian screening tests or with age (Kenen et al., 2003a; Werner-Lin, 2007; Foster et al., 2002). Interestingly, women at risk often identify a 'danger zone', a specific age at which they perceive their own cancer risk to increase dramatically (Werner-Lin, 2007). Often, this age is the earliest diagnosis age in the extended family or the diagnosis age of a close relative (Foster et al., 2002). Sometimes, after a family member has passed this perceived 'danger zone' without getting cancer, she feels less at risk (Foster et al., 2002).

Importantly, family stories based on misconceptions or secrecy, or danger zones determining the saliency of risk, can conflict with the scientific information presented by a genetic counselor. Information presented in the genetics consult that corresponds with the family 
stories is fairly likely to be retained (Foster et al., 2002), however, when the scientific information conflicts with the family stories, the counselee often deems the information inapplicable to their particular family and instead defaults to their family history and prior family beliefs (Foster et al., 2002; Werner-Lin, 2007). Counselees that accept the genetic counselor's information in lieu of their family stories can sometimes meet adverse reactions when presenting the new information to family members who prefer to believe the family stories (Kenen et al., 2003b).

Kenen et al. (2003b) were interested in more broadly investigating the processes by which women with strong family histories of cancer make decisions about their risk in both existential and genetic terms and about how to control their risk. This group found that, relative to women with a less severe family history, women who had many cases of cancer in the family and those who had a mother or sister die young more often tended to make use of heuristics, cognitive shortcuts that help people make decisions without having to consider large volumes of new and difficult information. One heuristic is 'availability', in other words instantly recalling sad memories of the loss of a loved one, and using the memories to help make a decision. This could be the basis of the salient personal risk perceived by women who lost relatives to cancer. Family stories about risk could be used as a heuristic, helping to make decisions on personal risk and genetic testing when the alternative is considering the complicated, confusing and new information presented in a genetics consult. 


\subsection{DECISIONS ABOUT UPTAKE OF GENETIC TESTING IN THE CONTEXT OF THE FAMILY}

When presented with the option of testing for BRCA mutations, it seems that members of such families consider numerous factors. Among these, they consider the implications for not only themselves but also for their family members (Foster et al., 2002; Kenen et al., 2003a; Kenen et al., 2006; Hallowell, 1999; Goelen et al., 1999). Taking the lead from Gilligan (1982) who studied psychological theory of women, Hallowell (1999) suggests that individuals (especially women) considering testing think about implications for their family because they are thinking of themselves as 'selves-in-relation', defining themselves in terms of their relationships with and obligations to their family. The research that characterizes this idea is presented here.

Many research participants stated that getting information for family members was an important reason to have BRCA testing (Hallowell, 1999; Tercyak et al., 2007; Phelps et al., 2007; Foster et al., 2004; Daly et al., 2001; Goelen et al., 1999; Foster et al., 2002; Hallowell et al., 2003). Some went a step further and insisted that it was their duty, obligation or responsibility to pursue testing (Hallowell et al., 2003; Hallowell, 1999; Kenen et al., 2003a) because they perceived that their family members had a right to know their own risk for cancer (Hallowell, 1999; Daly et al., 2001). Research participants sometimes approached testing as a chance to 'do right' by their families (d'Agincourt-Canning, 2001) or to fulfill their obligations to care for other family members (Hallowell et al., 2003), benefiting their families by providing information that could allow them to protect themselves from cancer (Goelen et al., 1999; d'Agincourt-Canning, 2001).

The decision to have testing was also sometimes made to gain information that might help them fulfill the obligation they felt to stay alive for their family members (Kenen et al., 
2003a; Hallowell, 1999; Foster et al., 2002). Mothers of young children (Kenen et al., 2003a) and women whose own mothers had been ill or had passed away when they were children (Hallowell, 1999; Foster et al., 2002) especially felt an obligation to survive. Women who lost their mothers at young ages tended to still be haunted by the helplessness they felt while watching their ill mothers and wanted to protect their children and loved ones from similar experiences (Hallowell, 1999; Foster et al., 2002).

Women also tended to feel obligated to have testing if a dying relative had alerted them to the hereditary nature of cancer in the family. They seemed to recognize that these dying family members had felt responsible to warn them of this, and so they in turn felt responsible to act on this information and to use it to reduce the chance of repeating the cancer histories of their relatives (Hallowell, 1999; Kenen et al., 2003b).

Therefore, the decision to have genetic testing is often made in the context of a high perceived personal risk for cancer but also by placing importance on the implications of genetic testing for family members.

\subsection{POST-TESTING REACTIONS OF THE TESTED INDIVIDUAL}

Not surprisingly, after deciding to pursue $B R C A$ testing, individuals tended to react to their test result according to its implications for their own risk, management and self-identity (Kenen et al., 2003a), but also according to its implications for family members. The following summarizes this latter observation.

In several studies, parents were clearly still acting as selves-in-relation after receiving their test result. Those identified to have a BRCA mutation often felt upset or guilty because they 
may have already passed the mutation on to their children (Kenen et al 2003 Nov, d'AgincourtCanning, 2001), even though they recognized that passing along the mutation was a chance event and not under their control (Speice et al., 2002; Bradbury et al., 2007; d’Agincourt-Canning, 2001; d'Agincourt-Canning, 2006). Parents testing negative also considered their result in terms of others. Generally, they felt relieved that they could not have passed the mutation on to their children (d’Agincourt-Canning, 2001; d’Agincourt-Canning, 2006).

Some individuals testing positive saw their result as a confirmation of what they had always assumed about the hereditary nature of the cancer in their family. For these individuals, the positive result had very little impact since there was often an underlying expectation of cancer in their future (Werner-Lin, 2007; d’Agincourt-Canning, 2006).

Also, it appears that the prior testing experiences and results of close family members like siblings could influence the way an individual perceives his or her own test result. For instance, individuals testing negative sometimes felt guilty if close family members had tested positive (d’Agincourt-Canning, 2006), a phenomenon often referred to as ‘survivor guilt'. To learn more about this, Smith et al. (1999) administered questionnaires that measured the testrelated distress for individuals one week after receiving their BRCA test result. The participants were members of several sibships in a Mormon family, the largest known kindred identified to have a BRCA1 mutation. For the males in the family, carrier status on its own was found to have little impact on distress level. However, relative to a noncarrier male, a carrier male had more distress if he was the first sibling tested than if all of his siblings (especially sisters) had already tested negative. Furthermore, noncarrier males whose siblings (again, especially sisters) tested positive seemed to be more distressed than noncarrier males whose siblings all tested negative. These results imply that men might feel distress because their sisters are at risk of cancer due to 
the existence of the mutation in the sibship. For women, carrier females experienced more testrelated distress than noncarrier females, as would be expected due to the substantial cancer risks that female mutation carriers face. Interestingly, however, carrier females who had at least some siblings that had already also tested positive experienced less distress than carrier females who did not have any siblings that had tested positive or who were the first of the sibship to have testing. Although these results should be replicated in a sample that can be generalized, these results provide further evidence that individuals having a $B R C A$ test interpret their results in terms of others.

\subsection{DISCLOSURE OF THE TEST RESULT TO FAMILY MEMBERS}

Since individuals' testing choices and interpretations of test results are so intimately enlaced with considerations of implications for family members, it is important to ask also what tested individuals do with their test results. What are the reasons for or against informing family of the results? How and when do they choose to do so? How do they feel about informing them? These questions will be addressed in the current section. But first, a caveat: Most studies about disclosures have focused on disclosures of a positive result, however some have extended to those who are hypothesizing about disclosures to family members after testing, as well as those disclosing the information they learned at a genetic counseling session, with or without having a genetic test result. This section will consider all of these. To facilitate clarity, individuals who were tested and who have the information to tell will be referred to as the 'tellers' or the 'potential tellers'. Family members they have told or are considering telling will simply be referred to as the 'family members' or 'relatives'. 


\subsubsection{What are the reasons individuals give for wanting to disclose their genetic information to their relatives?}

Not surprisingly, the most important and common reason for deciding to disclose genetic information to biological family members was that it could be important and useful for their family members to know, since it would provide them with information about their own risks and options for testing or management (Hughes et al., 2002; MacDonald et al., 2007; McGivern et al., 2004; Claes et al., 2003). As they did when considering whether to pursue testing, some individuals stated that their family members had a right to know the genetic information (d'Agincourt-Canning, 2001; Green et al., 1997) and that, by disclosing this information, they were fulfilling their duty to inform them (d'Agincourt-Canning, 2001; McGivern et al., 2004; Claes et al., 2003; Kenen et al., 2003a). Other reasons for disclosing information to family members were that the family member had actively stated an interest in knowing the test result or genetic information (Claes et al., 2003) or the family member themselves had already gone to genetic counseling or had genetic testing (Claes et al., 2003). An additional reason was to gain support or help in next steps. For instance, some women disclosed their test result in order to get advice and emotional support from family members regarding surveillance and surgical decisions (Hughes et al., 2002; McGivern et al., 2004). This reason was most important when women found to carry a mutation disclosed their result to their sisters (Hughes et al., 2002; McGivern et al., 2004). Some individuals chose to disclose their results to certain family members, especially partners, so that they could get help in disclosing the result to other family members like their children (Goelen et al., 1999; Hallowell et al., 2005a). 


\subsubsection{Factors that have been found to increase the likelihood of disclosure}

Several factors have been found to correlate with an increased likelihood of disclosure to family members. Considering them here serves as a start in appreciating what people think about when deciding whether to disclose test results and other genetic information to their family.

Generally, women are more likely to disclose genetic information to their family members than are men (Bradbury et al., 2007; Forrest et al., 2003; d’Agincourt-Canning, 2001). As well, personal medical history, family history, family structure and communication seem to play a role. Individuals receiving conclusive genetic testing results were found 6.25 times more likely to disclose their test result than individuals receiving an inconclusive result (Claes et al., 2003). Also, a personal history of cancer or prophylactic mastectomy was found to correlate with a higher rate of disclosure to family members (Julian-Reynier et al., 2000; Bradbury et al., 2007). Distant relatives were found more likely to receive genetic information in families having a greater number of deceased family members, while tellers close to a family member with cancer were found less likely to disclose positive results to their own mother (Claes et al., 2003; Julian-Reynier et al., 2000). Additionally, brothers were more likely to be informed if the mutation came from the paternal side of the family than if it was passed from the maternal side (Patenaude et al., 2006). As well, fathers appeared more likely to be told if they had a personal history of cancer, possibly because the fathers who had cancer were perceived to be more interested or open to discussing cancer-related topics (Patenaude et al., 2006). Indeed, openness about cancer in the family in general, as well as family cohesion and support, have been associated with higher rates of disclosure (Claes et al., 2003).

Age of the teller also seems to have an influence. Younger women were found more likely to disclose information to their distant relatives (Claes et al., 2003) and also to their mother 
(Claes et al., 2003; Julian-Reynier et al., 2000; Patenaude et al., 2006) than are older women. Julian-Reynier et al. (2000) suggested that the latter observation might be because older women are trying to protect their (typically older) mothers from disturbing information or because they do not perceive the information as useful for their mothers. Patenaude et al. (2006) present a similar interpretation, adding that perhaps older parents are thought to be less able to understand genetic information. They also point out that younger women tend to have younger mothers who could still be at significant hereditary cancer risk themselves (Patenaude et al., 2006). Older women are more likely to disclose test results to their own children (Julian-Reynier et al., 2000), likely because their children are typically older and closer to imminent genetic risk. Accordingly, older child age has been directly associated with more disclosures to children (Bradbury et al., 2007).

\subsubsection{Barriers or deterrents to disclosing information to relatives}

Several barriers or deterrents make disclosing genetic or testing information to family members difficult, sometimes preventing the disclosure process all together. The following outlines those factors identified in studies to date.

The most commonly found reason for not disclosing results to certain relatives was that potential tellers were either out of touch with their relatives or not emotionally close with them (Green et al., 1997; Forrest et al., 2003; MacDonald et al., 2007; Daly et al 2001; Hughes et al., 2002; McGivern et al., 2004; Claes et al., 2003). This trend was seen more frequently as the reason for not informing genetically distant relatives than for close relatives (Claes et al., 2003). In fact, many potential tellers did not seem to feel an obligation to inform family members who they did not know or who they were not in touch with (d'Agincourt-Canning, 2001; Green et al., 
1997). Interestingly, this loss of contact or emotional distance can sometimes be due to the difficult family history of cancer, as deaths can cause branches of the family to lose touch with each other, family members can distance themselves because of the emotional pain caused by the family cancer experience, or family members can have rifts due to matters concerned with care of their sick and dying family (Green et al., 1997).

Potential tellers were also concerned that sharing the information would alarm or upset others in the family, especially when a BRCA mutation was identified (Hallowell et al., 2003; MacDonald et al., 2007; d'Agincourt-Canning 2001; Green et al., 1997; Daly et al., 2001; Hughes et al., 2002; Kenen et al., 2007; Bradbury et al., 2007; Blandy et al., 2003; Hallowell et al., 2005a). As outlined above, individuals pursue testing largely because they feel an obligation to provide beneficial information for their family. However, upon testing positive for a mutation, some individuals seem to feel that the disclosure of bad news conflicts with what they feel is their obligation to care for their family (Hallowell et al., 2003; Hallowell et al., 2005b; Hallowell et al., 2005a; Green et al., 1997). In weighing the pros and cons of disclosing bad news, tellers considered the vulnerability of family members (Hallowell, 1999; Hallowell et al., 2005b). Some tellers were able to overcome their concerns and fulfill the duty they felt to inform their family members, often by clinging to the hope of scientific progress (Hallowell et al., 2003). Others felt that the potential for disturbing or upsetting their relatives outweighed the benefits of disclosing, at least for the time being (Hallowell, 1999; Bradbury et al., 2007; Hallowell et al., 2005a; Hughes et al., 2002).

Other less commonly mentioned barriers or deterrents for disclosures to family members included geographic distance (MacDonald et al., 2007; Green et al., 1997), the assumption other relatives would disclose the information to family members (Claes et al., 2003), dilemmas 
between family members about how to best disclose to others (Hallowell et al., 2005a), the teller's lack of confidence in their own communication skills (Daly et al., 2001; MacDonald et al., 2007), the fear that the information would be misunderstood by family members (Hughes et al., 2002; Hamilton et al., 2005) and thinking the information would not be useful to the family member (Forrest et al., 2003; MacDonald et al., 2007; Daly et al., 2001; Claes et al., 2003).

\subsubsection{Who are chosen as recipients of results?}

Typically, tested individuals disclose their results to at least one relative, whether the results are positive, negative, or inconclusive (Patenaude et al., 2006; d'Agincourt-Canning, 2001; McGivern et al., 2004; Costalas et al., 2003). In a study by McGivern et al. (2004), 46\% of mutation carriers informed less than half of their relatives. In a study by Costalas et al. (2003), probands who tested positive for a mutation shared their results with $83.7 \%$ of relatives, those who tested negative shared the results with $76.9 \%$ of relatives, and those who had an indeterminate result shared the result with $64.9 \%$ of relatives.

In general, first degree relatives were more likely to be told of test results than more distant relatives (Blandy et al., 2003; McGivern et al., 2004; Claes et al., 2003; MacDonald et al., 2007). Distant relatives were more likely to be informed of a conclusive test result than an inconclusive result (Claes et al., 2003; Hamilton et al., 2005; Hughes et al., 2002).

Many studies found that sisters were more likely to be told of test results than were brothers (Hamilton et al., 2005; McGivern et al., 2004; Claes et al., 2003; MacDonald et al., 2007). This could be because of the greater cancer risks in sisters compared to brothers in these families, especially if the teller were found to have a mutation. As well, sisters may be preferentially told if they have a closer relationship to the teller than brothers do, especially when 
discussing a 'female' topic like breast or ovarian cancer. This gender difference in disclosures might extend to offspring, as daughters were found more likely to be told than sons in some studies (Blandy et al., 2003; Patenaude et al., 2006; MacDonald et al., 2007). A similar trend may be seen in more extended relatives (Claes et al., 2003).

Regarding disclosures to offspring, Bradbury et al. (2007) noted that the majority of adult and late adolescent children were told about their parent's mutation or the hereditary risk of cancer. Parents were less likely to disclose this information to younger children (Patenaude et al., 2006; Bradbury et al., 2007).

Results are also frequently relayed to a spouse or partner (Julian-Reynier et al., 2000), although further comment on this is out of the scope of this review.

\subsubsection{The disclosure process}

\subsubsection{When and how does the disclosure happen?}

The trends characterizing disclosures to family members are varied. It is important to realize that disclosure choices are likely heavily influenced by the expectations, beliefs and norms for each family as well as interactions among relatives. Hamilton et al. (2005) found that some participants told their family members shortly after receiving the BRCA test results. Hughes et al. (2002) found a similar trend, in which test results were communicated to $25 \%$ of sisters on the same day as the disclosure session and to $70 \%$ of sisters within one week of the teller learning their own result. Female relatives were more likely to be told in person, while male relatives were more likely to be told over the phone or indirectly by other relatives (McGivern et al., 2004). 
Disclosures performed later tended to be more carefully thought out (Hamilton et al., 2005), as individuals appeared to consider a number of factors when deciding when and how to disclose their results to family members.

Firstly, the tested individual needed to decide who would disclose their test results to certain family members. Individuals sometimes relied on certain family members as a liaison between them and other branches of the family (d'Agincourt-Canning, 2001). Within a kinship, parents were generally thought to have the primary responsibility to pass on information to their own offspring, suggesting 'vertical' authority within these families (Forrest et al., 2003; Blandy et al., 2003; McGivern et al., 2004). For instance, a woman receiving a positive test result might inform each of her siblings (or siblings-in-law), who would then decide whether to inform their own offspring. People most likely to be placed in these liaison positions included women, even if they are not biologically at risk themselves (Hallowell et al., 2005b; d'Agincourt-Canning, 2001; Forrest et al., 2003), or family members seen to have some authority or special knowledge, such as a medical doctor in the family (Blandy et al., 2003). Studies have found that the help of health professionals in actually disclosing information is generally not wanted, however counseling or support in preparing to disclose could be useful (Bradbury et al., 2007; Tercyak et al., 2007).

The readiness of the teller was also found to be considered (Hamilton et al., 2005), as individuals discovering that they carry a $B R C A$ mutation often required time to adjust to the implications for themselves before telling other family members (Bradbury et al., 2007). As well, the readiness of the family member to receive the information was considered, particularly when the disclosure could provoke anxiety or stress (Hamilton et al., 2005; Hallowell et al., 2003). To assess if the family member was ready, the teller considered the family member's 
personality and life situation (Hamilton et al., 2005). For instance, certain family members could be perceived to be particularly vulnerable to receiving the information, especially those relatives who are young, unmarried, consequently identified as mutation carriers, or currently battling cancer (Bradbury et al., 2007). In addition, the setting and method of the disclosure is considered. In some cases, wanting to disclose the information in a particular setting was the reason for delaying disclosure (Hamilton et al., 2005). For instance, some individuals chose to delay the disclosure until their adult children returned from college or until a family gathering for some other reason like a holiday (Bradbury et al., 2007; Green et al., 1997). It has been suggested that one reason for waiting until seeing family members in person is so that the teller could integrate the disclosure into the conversation that would be taking place already, or so that they could reduce the alarming effect of contacting a more distant relative solely for the purpose of telling them about the mutation (Forrest et al., 2003; Green et al., 1997). Similarly, Green et al. (1997) found that some individuals disclosed to distant relatives by including the information about the mutation in a regular communication like a Christmas card letter. Still others decided to disclose the mutation and heritable cancer risks to family members, especially children, gradually over months or years (Bradbury et al., 2007).

\subsubsection{What information is disclosed?}

It is also important to consider what information is included in a disclosure to family members and what topics are discussed afterward. Studies by Hamilton et al. (2005), Kenen et al. (2006) and Hallowell et al. (2005a) showed that tellers tended to select what to disclose, sometimes omitting or altering information.

Disclosures sometimes involved downplaying the seriousness of the implications of the mutation, also in an effort to prevent anxiety in their relatives (Daly et al., 2001; DudokdeWit et 
al., 1997). Studies also show that several misconceptions about mode of inheritance, cancer risks or meaning of the test result are included in disclosures (Kenen et al., 2003b; Blandy et al., 2003; Claes et al., 2003). Other topics of discussion with family members were feelings about their own and their relatives' risks (Hughes et al., 2002; McGivern et al., 2004), screening and surgery guidelines, risk of a mutation for family members, cost of testing, and insurance discrimination (McGivern et al., 2004).

What is said during a disclosure can depend on the communication with family members before and during testing. Hallowell et al. (2005a) outlined that parents tended to adopt one of three communication strategies during this time: complete openness, limited disclosure, or total secrecy. With complete openness, children had been informed about genetic testing and its implications before their parent had testing and they were one of the first to learn the result. They knew the full extent of the implications of the mutation. With limited disclosure, parents limited what they told their children about the testing process until after receiving the results. Thus, the children in these families were not always prepared for the result. In families with total secrecy, the parent's involvement in testing was kept a guarded secret until after testing was through. Thus, the disclosure was usually a complete surprise for these children. In choosing the communication strategy, the parents in this study seemed to balance their children's rights to know the information with the parental duty to protect their children from potentially needless anxiety.

\subsubsection{How do the tellers feel about making the disclosure?}

Making a disclosure can evoke unexpected and intense emotions (Speice et al., 2002). For instance, for some individuals, particularly those who were the first in the family to be identified 
to have a BRCA mutation, the process of disclosing the mutation to family members is burdensome or upsetting (Hallowell et al., 2005b; Costalas et al., 2003). As eluded to previously, one reason is that individuals can feel guilty or burdened for 'being the bearer of bad news', revealing the existence of a familial BRCA mutation to their family members (Hamilton et al., 2005; Kenen et al., 2006; McGivern et al., 2004; d'Agincourt-Canning, 2001), especially when the family already had experienced emotional hardship regarding the death of a close family member (McGivern et al., 2004). Also, individuals may feel pressure to educate their family members about complicated genetic information that they may not themselves understand well (Kenen et al., 2006; DudokdeWit et al., 1997; Costalas et al., 2003).

\subsection{REACTIONS OF FAMILY MEMBERS TO THE DISCLOSURE AND EFFECTS ON FAMILY RELATIONSHIPS}

Initial reactions of family members when receiving news of a mutation from the teller are varied and undoubtedly motivated largely by emotion. Both the genetic information and these reactions can have a longer-lasting impact on family relationships. The following will serve as a review of reports in the literature that describe initial reactions from family members and effects on family relationships.

Some family members react to the news by feeling shocked, afraid, resentful, sad, guilty, angry, or blameful (Speice et al., 2002; Bradbury et al., 2007; Costalas et al., 2003). Anger or resentment could be because of the timing or the way in which information was given (Hallowell et al., 2005b) or, for family members preferring not to know, because the disclosure occurred at all (DudokdeWit et al., 1997). Strong emotions could manifest from concern about one’s own 
cancer risk or a family member's risk (DudokeWit et al., 1997) or because the grief or tension from a past loss of a family member is reactivated with this news (DudokeWit et al., 1997; Speice et al., 2002).

Additionally, some family members either did not seem to understand the significance of the result (Bradbury et al., 2007; Costalas et al., 2003; Blandy et al., 2003), seemed to be in denial of its significance or were not convinced of the result's implications (Speice et al., 2002). This last reaction was most common when the result was negative, as some relatives, such as children of parents testing negative, were still convinced that their health was at stake (Hallowell et al., 2005a, 2005b). Other family members interpreted a positive result not as upsetting but as an explanation for the strong family history of cancer (Bradbury et al., 2007). Likewise, some family members paid less attention to the news of the mutation than to a recent cancer diagnosis in the family (DudokdeWit et al., 1997).

In addressing the teller's genetic risks, it was noted that some relatives did not know what to say to them (Kenen et al., 2006) or were overly comforting to the teller (Kenen et al., 2006).

After learning of the existence of the family's mutation, some biological relatives eventually chose to be tested for the mutation as well. Blandy et al. (2003) studied the uptake of testing in close biological family members. They found that the average testing participation among informed high risk relatives was 15\% (29\% for first degree relatives and 12\% for nieces), and that in $37 \%$ of families no close relatives requested testing. In this study, the choice to have testing was positively associated with greater family support and better knowledge of the risk of genetic transmission by women.

If family members do not share the same coping style as the teller, he or she can feel frustrated or sad (Speice et al., 2002). This was especially evident when relatives did not seem to 
want the genetic information or did not want to pursue genetic testing (d'Agincourt-Canning, 2001; McGivern et al., 2004; Blandy et al., 2003). Members of the family sometimes started to feel isolated from each other, especially if they were not sure how best to communicate with each other, or if they felt they were in different life stages (Kenen et al., 2006; Hamilton et al., 2005; Werner-Lin, 2007; Speice et al., 2002). For instance, one research participant in WernerLin's study (2007) tested positive for a BRCA mutation, as did her older sisters; however she felt isolated from her sisters because they were all married with children while she was not. There can also be family discord, especially when family members disagree about the implications of the mutation for the family (Speice et al., 2002) or about who should be informed (Forrest et al., 2003).

On the other hand, having the mutation in the family can have positive effects on some family relationships. For instance, one research participant stated that she had been feeling lonely after her breast cancer diagnosis but upon finding that she shared the BRCA gene with her family members she felt consoled, because it then became a problem the family could address together (Kenen et al., 2006). d'Agincourt-Canning (2001) found that genetic testing allowed her research participants to strengthen interpersonal ties by providing family members with valuable information. The study by Bradbury et al. (2007) on the effect of genetic testing on the overall family relationship found that while $65 \%$ of individuals reported no change in their relationship with their offspring upon disclosure of the test result, 22\% reported a strengthening of their relationship. Also, McInerney-Leo et al. (2005) found that perceptions of family cohesion increased upon making a testing decision. Interestingly, in this study family cohesion seemed to increase even if the decision was to not pursue testing. 
In many families there were reportedly no significant changes in overall family functioning, relationships, or family conflict (McInerney-Leo et al., 2005; Bradbury et al., 2007; Stroup and Smith, 2007).

Importantly, testing positive for a BRCA mutation can often impact the relationship with a spouse, including strengthening or weakening the partnership. Review of this is beyond the scope of this paper.

\subsubsection{How do families talk about having a BRCA mutation?}

One interesting way to assess the effect of $B R C A$ testing on family relationships is to ask about conversations in the family regarding the mutation, cancer, cancer risk, or surgeries after a genetic testing result has been disclosed. So far, few studies have focused on this question but some preliminary observations have been made. One research participant relayed that after her sisters' and her cousin's diagnosis 'family life became dominated by conversations about cancer...consumed with fad cures, drinking gallons of green tea and sprinkling flax seed on the children's breakfast cereal' (Werner-Lin, 2007). On the contrary, other families seem to contain some family members who felt stigmatized and thus were very resistant to talking about the inherited breast/ovarian cancer in the family (Kenen et al., 2007). This can create 'areas of sensitivity', further discouraging these conversations (Bradbury et al., 2007), and can cause other family members to feel shunned at family events by relatives not as open to discussing it (Speice et al., 2002).

McInerney-Leo et al. (2005) measured the expressiveness within families over time after $B R C A$ testing and noted that at 6-9 months after testing there was a trend toward a reduction in expressiveness. They suggested that this trend could reflect an initial tendency to express 
emotions about the test result to friends or other individuals outside the family rather than to their family members, who may be upset and concerned about their own risk or the risk of their family.

\subsection{METHODOLOGY OF THE STUDIES OUTLINED ABOVE}

Many of the studies outlined above were quantitative studies, in which trends were discerned by analyzing questionnaires that measure specific elements. While these studies are valuable in characterizing some components of the experience of members of hereditary breast/ovarian cancer families, they do not allow researchers to discover and characterize issues that researchers do not anticipate (Beeson, 1997). However, a thorough understanding of the full breadth of experience is required for health care professionals like genetic counselors to effectively and empathetically interact with members of these families.

Qualitative research, sometimes using open-ended interviews, can provide a way to detect unexpected experiences of these families since it is the research participants themselves that lead the direction of the study. Qualitative research is often about exploring meaning; it attempts to understand both what people do and why they do it (Beeson, 1997). Qualitative work may also place importance on all observations no matter how deviant from the 'norm' they are. Thus, qualitative work can be very useful for health care professionals to sensitize themselves to the experience of the individuals or families they are meeting with.

Several qualitative studies have been performed to describe the perception of risk and the experiences people have as part of a family with a strong history of breast/ovarian cancer, as outlined above (Kenen et al., 2003a; Phelps et al., 2007; Raveis and Pretter, 2005; Werner-Lin, 
2007; Hallowell, 1999; Foster et al., 2002). Others have focused more on the testing decisions and on family communication of genetic information including disclosures of $B R C A$ test results (Green et al., 1997; Hallowell et al., 2003; d'Agincourt-Canning, 2006; d'Agincourt-Canning, 2001; Forrest et al., 2003; Foster et al., 2002; Goelen et al., 1999; Hallowell et al., 2005a; Hallowell et al., 2005b; Hamilton et al., 2005; Kenen et al., 2004). There have been very few qualitative studies performed to date that have focused specifically on the impact that BRCA testing has on family relationships. Notable exceptions are an early case description by DudokdeWit et al. (1997) of a family testing for BRCA, and a study by Speice et al. (2002), using a family-oriented psychoeducational group for women who tested positive for a BRCA mutation. A few other studies investigating general effects or impact of BRCA testing noted some changes in family relationships as part of their results (Kenen et al., 2007; Kenen et al., 2006). Considering this, there is a paucity of qualitative studies that characterize the impact of $B R C A$ testing on families and the relationships between family members. 


\subsection{AIM OF THE STUDY}

The current study served as a secondary data analysis of a qualitative study investigating the impact of BRCA testing on family dynamics and the relationships between family members. 


\subsection{METHODS AND PROCEDURES}

The initial study, including recruitment and interviews of participants, was conducted by Dr.

Rebekah J. Hamilton and was approved by the Institutional Review Board (IRB) (0509094). Data from some of these interviews, regarding disclosure of genetic test results to family members, have been published previously by Hamilton et al. (2005). The secondary analysis of the interviews, constituting the current study, was approved by the University of Pittsburgh IRB (PRO07080253).

\subsubsection{Interviews with research participants}

The qualitative research design conducted in the initial study included open-ended interviews with members of families who have confirmed or probable hereditary breast/ovarian cancer syndrome. Grounded theory methodology was employed during the interviewing for that study. Grounded theory methods involve simultaneous collection and analysis of data in order to build theoretical frameworks that explain the data. Additional data collection is based on the ongoing analysis, helping to further develop the theoretical frameworks (Charmaz, 2000). The interviews used in the current study were thus suitable for a complete grounded theory analysis to be performed if desired. However, a more limited scope was employed using secondary analysis to identify themes (see below). 
Phone or in-person interviews are the more traditional form of data collection for qualitative studies using interviewing as part of data collection. However, recently email interviews have been introduced as an appropriate alternative, as outlined by Hamilton and Bowers (2006). Therefore, interviews of participants in the initial study were performed either over the phone or by email, depending on the participants' preferences. All interviews were performed by Dr. Rebekah J. Hamilton. Of all participants interviewed by Dr. Hamilton, those who had participated in two interviews - an initial interview and another approximately three years later - were chosen for secondary analysis in the current study.

\subsubsection{Participant recruitment}

Study participants were recruited by posting notices on a hereditary breast/ovarian cancer syndrome support website (FORCE: Facing Our Risk of Cancer Empowered: www.facingourrisk.org). All participants gave informed consent prior to being interviewed.

\subsubsection{Transcription}

Telephone interviews were transcribed verbatim from audiotapes to Microsoft Word by a professional transcriptionist. Personal identifiers were removed in accordance with the IRB, and participants were given pseudonyms. Transcripts preserved the participants' and the interviewer's grammar, unfinished sentences, pauses, and placeholders as best as possible. Email interviews did not require transcription so were copied and pasted into Microsoft Word. Interview passages that were included in this report were subject to minor revision only when it was judged that the revision would not take away from the meaning of the passage but would 
facilitate easier understanding of the passage by the reader. Examples of revision include correcting spelling and grammar mistakes and removing some of the interviewer's minor contributions to telephone interview transcripts.

\subsubsection{Thematic analysis as the method of secondary analysis}

Secondary analysis in qualitative research is defined by Thorne (1994) as the analysis of data either beyond its original intent or in relation to new and extended inquiries. It is often performed by individuals who were not involved in the initial study design or collection of data (Thorne, 1994). The current study is classified as secondary analysis since it represented an extended study of the interview transcripts and was performed by an individual not previously involved with this study.

Thematic analysis was chosen as the most appropriate method for the secondary analysis of the interview transcripts. This is a method for identifying, describing, analyzing and reporting themes and patterns within data (Braun and Clarke, 2006). It was chosen because it is a flexible technique that can be used to analyze data obtained under a number of qualitative theoretical frameworks, including grounded theory (Braun and Clarke, 2006), and because it is relatively easy and quick for new qualitative researchers to learn (Braun and Clarke, 2006). A drawback to using thematic analysis is that its methodology is not well-described and thus is open to interpretation especially at higher levels of analysis (Braun and Clarke, 2006). However, it was judged that the benefits to using thematic analysis for this study outweighed this drawback.

Thematic analysis allows for either a rich description of the data set related to a broad

research question or a detailed description of a particular theme within the data (Braun and Clarke, 2006). In the former scenario, typically the researcher is interested in gaining a cross- 
section of experiences related to their research question, and they use an inductive approach in which patterns and themes are linked to the data and are not fundamentally driven by the researcher's prior theories or preconceptions (Braun and Clarke, 2006; Boyatzis, 1998). In the latter, researchers typically are interested in a very specific idea derived from reading the literature, from their prior research studies or from their clinic experience. These researchers tend to take a theoretical or deductive approach to their thematic analysis that derives from their pre-existing ideas (Braun and Clarke, 2006; Boyatzis, 1998). All thematic analyses include not only a description of the themes identified but also an interpretation of these themes, often in relation to previous reports in the literature (Braun and Clarke, 2006).

Since few qualitative studies had previously examined the effects of BRCA gene testing on family relationships, an inductive thematic analysis approach was chosen so that a crosssection of family effects related to BRCA gene testing could be explored. This data-driven approach would be of benefit also because it would allow identification of unexpected themes in the data (Braun and Clarke, 2006).

The following outlines the main steps performed during the thematic analysis in the current study.

\subsubsection{Becoming familiar with data and background literature}

All transcripts were read twice by the author before coding to gain an appreciation of the scope of the data set. Some preliminary notes were made upon reading each transcript. A comprehensive review of the literature, as summarized in the Background and Significance section, was also completed prior to coding the transcripts. This literature review was performed to sensitize the author to subtle concepts that may be present in the data but could be missed if not introduced to the author prior to coding. Charmaz (2000) encourages the use of sensitizing 
concepts such as literature searches and clinical experiences as points of departure from which to study the data. Likewise, Boyatzis (1998) asserts that knowledge relevant to the topic being examined is crucial, and that training in the area is also useful, in being ready to see what is in the data. Charmaz (2006a) highlights that when performing inductive qualitative analysis, it is important to remember that our prior perspectives represent only one view among many and that we must guard against imposing our preconceptions on the data, instead requiring that our preconceived ideas each earn their way into the analysis. The method used to generate codes, as outlined in the next section, was critical for preserving the integrity of the data in this way.

\subsubsection{Generating initial codes}

Coding is a process that defines what the data are about (Charmaz, 2006a). The simplest definition of a code is a 'label' that describes the data (Boyatzis, 1998; Richards and Morse, 2007). However, coding is also the first analytic step in thematic analysis, as coding pushes researchers to try to understand what their research participants meant when making statements, as well as to look at statements in ways that may not have occurred to the participants themselves (Charmaz, 2006a). Codes can ultimately represent links between the data and an idea (Richards and Morse, 2007) and can be organized into categories or themes based on their content or motivations. After initial coding, the category or theme, rather than each individual code, becomes the focus of attention (Richards and Morse, 2007).

Initial coding in an inductive thematic analysis is driven by the goal to remain open to all possible interpretations. As Richards and Morse (2007) describe it, initial coding involves creating a mixture of descriptive codes and topic codes. Descriptive coding involves storing information known about data items (Richards and Morse, 2007), for example the research participant's age, number and sex of siblings and children, whether they had tested for a BRCA 
mutation and whether a mutation was found upon testing. This type of coding is not subject to much bias since it focuses on facts. Topic coding, however, is a far more analytic activity, as Richards and Morse (2007) point out here.

Topic coding...entails creating a category or recognizing one from earlier, reflecting on where it belongs among your growing ideas, and reflecting on the data you are referring to and on how they fit with the other data coded there.

Due to the potential for complexity in meaning, several topic codes can mark the same passage (Richards and Morse, 2007). Since topic coding is more analytic than descriptive coding, it is subject to more bias from the researcher’s background and preconceptions. To minimize bias, the topic codes in the current study were made as descriptive of the participant's experience or thought as possible. Sometimes, 'in vivo' codes, codes using the participants' own special terms, were created to help preserve the meanings of the participants (Charmaz, 2006a). More abstract or interpretative thoughts were recorded throughout the coding process in memos (see below).

The process of topic coding can be done using several techniques, two of which are outlined here briefly. Firstly, line-by-line coding involves giving at least one code to each phrase, line or sentence in the data set. Charmaz (2006a), a proponent of this method, asserts that coding each line challenges the researcher to be critical and analytical about what the participant is saying both explicitly and implicitly, rather than merely immersing herself in what the participants state are their worldviews. Secondly, Rennie (2006) suggests that coding 'meaning units' is sometimes more appropriate than line-by-line coding. He argues that people being interviewed wish to make a point, and when they have made it they move on to another. Thus, each 'point' is essentially a 'meaning unit', or an 'envelope of meaning' (Rennie, 2006) and each can be coded. While both Charmaz and Rennie provide guidance for coding during a 
grounded theory analysis, in doing so they may provide insight into coding for the purposes of thematic analysis as well.

For the current study, line-by-line coding was chosen because some participants seemed to be distracted and would sometimes flip back and forth unprompted between different topics, making meaning unit coding difficult. As well, a line-by-line approach encouraged attention to every detail in the transcript, something to which the researcher responded well. Therefore, lineby-line coding of the parts of the transcript that addressed the family was performed. Many of the transcripts also focused on management decisions and sometimes other subjects. These parts of the transcripts were not coded but were read in case they could have an influence on family relationships. If a connection was suspected, it was outlined in a memo.

Coding was facilitated by several tips made by Charmaz (2006a) and Boyatzis (1998), including attempting to stay close to the data, keeping codes short, simple and precise, preserving actions in the codes (i.e. using verbs ending in '-ing' whenever possible), moving quickly through the data, and not being distracted by personal concerns such as fatigue, sensory overload, frustration or confusion.

Grounded theory typically involves another level of coding performed after initial coding, called focused or selective coding (Charmaz, 2000; Charmaz, 2006a). In this phase, the most common, interesting or significant initial codes are used to sift through large amounts of data and select and develop only these significant topics (Charmaz, 2000; Charmaz, 2006a). This type of coding is generally more directed and conceptual than initial coding (Charmaz, 2000; Charmaz, 2006a). As inductive thematic analysis is a less directed and less theoretical approach to analysis than performing a full grounded theory, it was decided that focused coding was unnecessary for 
this analysis and instead the initial codes would be used to determine and characterize themes present in the data (see below).

In the current study, coding was facilitated by importing interview transcripts from Microsoft Word into QSR's Nudist Vivo (version 7.0.281.0 SP4), a software program that assists researchers in coding qualitative transcripts and in organizing the codes into candidate themes.

\subsubsection{Memo writing}

It is recommended that researchers write freely and often about their thoughts while coding and while identifying and describing themes. As Charmaz (2006b) says, 'memos catch your thoughts, capture the comparisons and connections you make, and crystallize questions and directions for you to pursue.' Memo writing thus provides a venue to express thoughts about individual codes, developing themes, and connections between themes.

There is no 'wrong' way or time to write a memo (Charmaz, 2006b; Richards and Morse, 2007). In the current study, memos were written from the onset of reading the interviews, throughout the coding process, and throughout the identification and clarification of themes. Looking back at earlier memos was useful in recalling each research participant's story, interesting points they discussed, and what the researcher was thinking during each stage of the process.

\subsubsection{Identifying and characterizing themes}

A theme in qualitative research is defined by Braun and Clarke (2006) as something that captures an important aspect of the data in relation to the research question. Representation of the theme across the data set is ideal but not necessary (Braun and Clarke, 2006). 
In the current study, identification and characterization of themes was a process. Initial ideas about themes were noted early on. Potential themes were described in memos throughout the initial stages of coding. After coding the interviews of the first few participants, codes were organized using the Nudist Vivo software into potential themes or subthemes depending on their content or motivation. Often, codes were classified under several themes. For each additional interview transcript, codes were organized into these preliminary thematic categories. At a few points throughout the analysis the codes were reorganized to better reflect the themes present in the data.

After all interviews were coded and all codes were classified under thematic headings, the themes and subthemes characterizing the codes were listed in a memo. Then, a preliminary thematic map was created, consisting of a visual map of each theme and the connections between them. From this, three major themes were selected to be the focus of the current paper. They will be described in the Results section. 


\subsection{RESULTS}

\subsection{CHARACTERIZATION OF THE SAMPLE}

The analysis involved 12 participants, all testing positive for either a BRCA1 or BRCA2 mutation. These 12 participants came from a total of eight families, since there were two families in which three family members participated in the study. All but one participant were female. Ages ranged from the mid-20s to the late-50s. Some participants had a personal history of cancer. Most participants were married or partnered, and most had biological children.

\subsection{THEMES IDENTIFIED IN THE ANALYSIS}

The thematic analysis identified several themes reflecting how testing positive for a BRCA mutation can impact family relationships. This paper will focus on three of these themes, since they were commonly mentioned and thus easiest to characterize with the available data. Additional themes will be listed later in this section. Importantly, as family relationships can be complex, so can the themes that were identified. Thus, although the three major themes described here have some distinct features from one another, they are also related. An overview of the connections between the three themes will be discussed after an explanation of each. 


\subsubsection{Theme \# 1: New or changed family roles for the index case}

The first individual in the extended family to pursue genetic counseling or testing is often referred to as the 'index case' of the family. After genetic testing, most of the index cases in the current study seemed to take on a new role in their families. Here this new role will be characterized.

\subsubsection{Obligation to inform family members}

Firstly, those index cases receiving news of their BRCA mutation usually felt obligated to inform relatives. Interestingly, this obligation was also felt by other participants who fit the role of index case in some sense. For instance, Claire was the first in her family to attend genetic counseling, due to her strong family history of breast and ovarian cancer. She had not been diagnosed with cancer so was not the appropriate person to test first in the family. However, she convinced relatives to pursue testing, and she organized a family meeting with the genetic counselor to discuss the likelihood of hereditary cancer in their family. She was also the first in the family to learn of the family's BRCA mutation. When asked about disclosing these results to her family, she clearly indicates the obligation she feels as the index case.

I was the first person in the family. I'm kind of the person who opened the can of worms. So, um, I felt that responsibility very heavily.

A similar sense of responsibility was expressed by Danielle, whose mother was actually the first in the family to have testing, but died only two weeks after learning that she carried a mutation. Danielle later had testing and discovered that she also carries the mutation. Danielle says:

I feel this huge sense of responsibility to let extended family know to kind of you know, if they want to be tested they can be. 
In this case, after her mother's death, Danielle seems to have assumed the role of 'index case by proxy', taking on the task of disclosing the result to her relatives since her mother never had a chance to do this before her death. Interestingly, although this participant wanted her distant cousin to know she possibly carried the mutation, she did not feel she had the right to actually tell her.

With my um, like I called my mom's cousin, who has breast and ovarian cancer and I was really worried about that because I didn't want, I mean we know she has the gene, without her being tested, but I was did not feel I had the right to say that and so wanted to tell her that my mom tested positive and that you know, I did and that uh, there's concern, kind of thing.

Thus, Danielle served the obligation she felt as the 'index case by proxy' to let this relative know of the test result without directly stating her assumption that the cousin has the mutation.

\subsubsection{Acting on the responsibility to bring news to the family can be burdensome}

\section{for the index case}

Upon feeling this responsibility to inform family members of the BRCA mutation in the family, most study participants took the primary role in dispensing the information throughout the family. This role of 'bringer of news' was not always easy, however.

For example, several participants felt upset when disclosing the news of the mutation to their family. Many felt guilty during the disclosure, even though they thought that guilt was an irrational feeling. This sentiment is best expressed by Judy, who was the first in her family to have genetic testing, several years after a diagnosis of breast cancer.

I almost had feelings that I had done something "wrong” and was confessing to them. Intellectually I know that is silly, but it was the feeling. Perhaps it was hard because it meant my breast cancer really was more than about me - and was now a factor for the whole family. And it was out of my control! Who wants to be the bearer of bad news? 
Interestingly, some index cases appeared to feel guilty even when the news of the family mutation was welcomed by family members. For instance, Monica, who chose to have a prophylactic mastectomy upon learning she carried the family BRCA mutation, recalls conversations she had with her aunt, the index case in her family, after her aunt sent a letter informing her of the mutation.

Interviewer: And how was that letter received in the family?

Monica: Um, funny. I'll say by us it was received by my immediate family and my mom and my sister and I, very positively and grateful. My aunt herself...had a little bit of, um...you know, guilt at times. When we've gone through it like... 'If I hadn't found out then they wouldn't have to go through that, you know.' What I've always thought was great that we know...And there was a couple times when I was having a hard time, at, the email that she wrote me a couple things, and I wouldn't call it quite this, but like an apology, but kind of just overwhelming emotion like, 'God you're going through so much. I can't, kind of like, I can’t believe what I started. I hope it didn’t open up too much.' And me in response, 'Oh my God, no. You know, I wouldn't, I made the decision to follow through with it, I wouldn't trade it for anything.'

Thus, the index cases who participated in this study tended to feel a special obligation to inform relatives of their mutation, but found that doing so could be burdensome due to the enormity of the implications of the news for their family.

\subsubsection{Index case as role model}

Getting cancer and testing positive for a BRCA mutation created a different burden for another participant, Elise, who was also the first in her family to have testing. After her cancer diagnosis and her positive BRCA test result, she felt pressured to act as a role model to her family, especially her younger siblings.

Interviewer: Can you talk some more about what it was like to be the "first" identified in your family and thus the one to tell the news? Do you think there has been any change in your relationships with your parents or siblings because of this?

Elise: It sucks to be first. I feel like I always have to have the answers and be the voice of reason. (I'm the oldest child and have always been maternal towards my brothers and sisters). So even though I'm a basket case to my sweet husband- to my brothers and 
sisters I feel like I have to be at peace with all of this. If I'm not, how can I expect them to be. I don't want them to live scared because of this.

She even explains how she communicates with her siblings so that she doesn't alarm them.

I wanted to be gentle with my brothers and sisters because I know that this type of risk is so difficult to deal with at such a young age. (Yes, the cancer patient was calming everyone else down. Doesn’t that seem backwards.)

In the first passage, this participant suggests that her established role as a maternal big sister might have encouraged her to act as a role model to her siblings in this situation. However, this particular participant's family history may also have provoked such pressure. Before her own breast cancer diagnosis at age 28, she did not know of any cancer history in her parents, aunts, uncles or cousins. Upon investigation after her diagnosis, the family discovered a strong cancer history in distant relatives that was consistent with a hereditary cancer syndrome. When asked if it might have been the lack of cancer in close family that is forcing Elise to be a role model, she agrees.

Interviewer: If you had known there was a "family history" of cancers in your family, do you think your response (i.e. feeling guilty) would have been different when the mutations were identified? How so?

Elise: I think it would have been different. I would have had someone else to point to- or someone else to relate to. I feel like I am setting the "standard" here. I.e., you should feel this way when diagnosed, you should feel this way after chemo. It's all new to my family. If we would have known, it wouldn't have been such a shock. Everything has felt like a big giant snowball picking up speed- maybe if we would have had some idea we would have been on more even ground with all of this. I would definitely not feel like I have to be such a role model about this whole thing.

Interestingly, Elise's mother, Evelyn, acknowledges her daughter's special role in the family but does not suggest that it has been burdensome to her daughter.

[Elise]'s been amazing because she's really been the one that has kept this um, almost all together and I even wrote her a letter just before her last chemo treatment just telling her how proud I was of her because she was the one we all took our cue from. She was the one that was always upbeat, um, very seldom did you see her down...I would just sit back in awe and say, this is my child, my child, and look at what she's doing. 
Although feeling pressured to be a role model was not common for the index cases in the current study, it was an important feeling for this participant and thus worthy of description. This situation also exemplifies that the burden felt by an individual after genetic testing may not be recognized by their family members. Moreover, it appears that her mother is reinforcing her daughter's burdensome behavior.

\subsubsection{Theme \# 2: Genetic testing affects discussions in the family}

The second major theme identified in the study was that a positive BRCA test result commonly impacted discussions between family members. The following outlines several different ways in which discussions were influenced in the current study.

\subsubsection{Testing facilitates conversations in the family}

For some individuals, receiving the news of a $B R C A$ mutation in the family resulted in more talk about cancer, cancer risk, or associated topics like prophylactic surgeries.

For example, genetic testing served as a catalyst for opening up Naomi's relationship with her father, which had been strained since Naomi lost her mother to breast cancer.

My dad and I have always had a pretty stilted relationship and a hard time talking about my mom - in a lot of ways having the concrete issues of the testing process to discuss made the whole issue more approachable. I also definitely felt his approval and relief that I was doing something about the cancer thing, so that has made our relationship somewhat more comfortable.

Likewise, Elise feels that the genetic testing she pursued following her cancer diagnosis opened up discussion about cancer and genes in her family. However, for her, these conversations sometimes have had a negative effect. 
My family is no longer as lighthearted as we once were. Genetic discussions happen all the time. I feel like there is absolutely no escaping this disease...Every time I pick up the phone someone else is calling to talk about my breasts.

Importantly, this is the same participant who felt forced to be a role model to her family, as described above. Interestingly, Elise's sister, Emily, does not perceive that genetic testing has fueled family discussions significantly.

The family doesn't talk about the mutation directly, except when the testing was done. Since the cancer is such a big part of our life, we don't really discuss the what-ifs of everyone else.

It is possible that the discord between these perceptions could be because Elise, the index case and first in the immediate family to get cancer, is likely at the center of most genetic conversations in the family while Emily, never diagnosed, may not be so intimately involved in such discussions. Their mother, Evelyn, sees genetic testing as having mostly a positive impact on their family discussions.

Interviewer: If you had to, if somebody just asked you a general question about, you know, what do you think the impact of having these predictive genetic tests in your family has been, how would you answer that?

Evelyn: I think that all and all it's been a very positive, um, it's given us a focus away from so much Elise having the cancer and saying OK, this is why Elise had the cancer, and again we'll do what we can do to try and not have it.

Thus, testing positive for a BRCA mutation seems to have the potential to open up discussions about cancer and genetics in the family, and this may be welcomed or unwelcome. An important observation is that different members of the same family can perceive the impact on their discussions differently.

Genetic testing for BRCA mutations promoted conversations for family $\mathrm{M}$ as well. Family $\mathrm{M}$ included a nuclear family that was already very close and talked about cancer frequently even before genetic testing, due to the strong history of breast cancer on Mike's, the father's, side of the family. 
Interviewer: When you all are together is [cancer] a common topic of conversation or not so much anymore or....

Mike: No, it's real common. Every single conversation. It always has been. Now of course it's much more personal.

Interviewer: Now when you say it always has been...before testing what was the conversation?

Mike: ...we didn’t talk about it quite that much.

In this family, genetic testing has encouraged Mike to be more in touch in general with his two daughters, who are in their 20s and who both tested positive for the mutation.

I think of them much more frequently now that um, this kind of news has happened and we communicate more regularly than we did before and that's, we've always been very close, but I just kind of have this feeling of, of I don't know, just maybe the time that I have with them is, really means a whole lot more to me now.

One of his daughters, Mary, notes a similar change in their relationship, saying:

And I think it's definitely, definitely hit my dad a lot harder than I thought it would, even though, again we're very close, but it, it's hit him in a way that I wasn't expecting. I think it's caused him to be um, like I said a little more um attentive to us, he puts the extra mile to make sure he has a conversation with us as opposed to like hearing conversations through my mom and getting an update on my new job or something through my mom. He calls up sometimes. I mean, like last week he called my sister at 7:30 in the morning and said 'Good morning, I just wanted to say hi and have a good day,' and she was like, 'What the hell?'

Thus, for some families, genetic testing can promote discussions not only related to cancer risk but general conversations as well. The reactions to these conversations may be positive or negative, and may be shared by family members or not.

\subsubsection{Disapproval of topic during family discussion}

In the families in this study, it was quite common that there were at least some relatives that did not want to talk about the family BRCA mutation. They let other family members know of their wish in various ways. An uncommon way was by directly telling them. Claire experienced an example of this. 
And one niece actually after I had told the family about the results sent message through her mother, my sister, that um, I had mentioned it, now once I told about it I could, um, basically damn well shut up now. It was pretty, she doesn't speak, she wouldn't say damn, she would not use those words, but um, yeah, it was, she was, she was really quite adamant that she did not want, and she said something to the effect of 'I don't want this coming up every time the family gets together. We don't need to talk about it.'

More often, family members used subtle, indirect messages to discourage talk of the mutation.

For instance, Danielle describes feeling this message from her siblings.

I mean they never bring it up now, I'm the one who has to bring it up. That's you know, I don't think they really want me to, anymore. There's certainly a subtle message. If I bring it up they'll talk about it but there's definitely a subtle, I guess a picture, 'this is not what we want to talk about.' And they won't ever bring it up. They'll ask me how I'm doing. But, and lots of ways want to know that, oh, everything's just fine. You know, they just don't want to know, don't want to uh delve into it too much.

Her siblings' hesitancy to talk about the mutation has been difficult for Danielle. She says:

Um, my sisters don’t like to talk about it, don’t want to deal with it, the two sisters that have chose not to be tested. And um that's very difficult for me because I need to talk about this and that's my way of coping.

Yet Danielle still seemed to want to keep her siblings informed about BRCA and cancer risks.

She adapted to her siblings' hesitancy by choosing methods to inform them other than directly talking to them about it.

And um, and I also am hesitant to keep you know, I don't want to, you know, it's a fine line and I don't want to push my sisters away...I get a sense if I continue to push this, that it's gonna really impact our relationship negatively and I don't want to do that...I mean, it's they know, they know what the risk is and they know what to do, they know who to contact. Um, we are fortunate enough [in their region] to have a support group...you know I send the news letters and that kind of thing, let them know when the speakers are happening...I think that's my work now instead of to keep bringing it up.

A very similar family dynamic was present in Claire’s family. In this family, Claire's siblings were supportive around the time of her prophylactic mastectomy, but were very hesitant to bring up related topics at other times.

We got together and nobody brought it up once. Like it was so, and for me it was so weird because it was just so important to me at the time. A couple times that happened. I 
just have heard, you know, about the family having the gene or something, and then we'd get together and we'd be talking about the weather, you know, it was like they, they didn't want to bring it up, or didn't know what, or just, I don't know, or didn't want me to bring it up. So it felt very odd for me because to me, I did want to discuss it with them and they weren't that interested.

In the $\mathrm{M}$ family, although several members were very open to each other about the mutation and cancer risk management, certain family members were not. Like these other two families, some family members did not acknowledge the mutation or even Monica's recent prophylactic mastectomy at family gatherings. Monica thinks these relatives were in denial.

Interviewer: Do they talk about it at all at family gatherings?

Monica: Yeah, but not unless um, the genetic issue, not unless my dad um, or [aunt] who's the one that sent out the letter, she brings it up. I mean the other five per se that haven't got tested or anything, it's a nonissue. I mean, that's the way it presents. Maybe in their private home, um, you know, there's some other discussion that I'm not aware about, but it's not discussed openly with the extended family. No. And it's, my classification on the outside is a big fat denial.

Monica also describes how her grandmother is a good example of one of these relatives.

Interviewer: Has your grandmother said anything to you?

Monica: Um, this is so, I hate this, this is funny. Now my grandmother is a very kind, very caring person, but the woman has serious denial issues. So they come to see me, my grandma, my aunt who's just been an absolute gem...just been such a support... I was in the hospital [after her prophylactic mastectomy], and I had a really hard time... And it's funny, my uncle, the baby that's 4 years older than me, um, who is, you know, my dad's half brother, um, wanted to come to the hospital. 'Oh, I wanna come with you guys, I'm gonna get cleaned up and I'm gonna come visit Monica' and my grandma, 'No, that's not appropriate.' And my aunt was pissed, and said 'What, Mom?' And she said, 'Oh no, no, no we're just gonna run out there and take her some flowers and we'll be back, we'll let you know.' And my uncle's kind of caught off guard says, 'But no, I wanna go see her.' And my aunt who's pissed at my grandma, and she's not the kind of woman that gets angry and confrontive to people and said, 'What cause he's a guy, he can't deal with it if it's a woman's issue?...Get your head out of the sand. This is family, this is everyone's issue. It doesn't matter, there's no gender cap on this.'

Like in Danielle’s family, having different coping strategies in the family can be a source of conflict, as appears to occur between Monica’s grandmother, who would prefer not to talk directly about the mastectomy, and Monica’s aunt and uncle, who are more open to discussing it. 
Later in Monica's interview she revealed that during this visit to the hospital her grandmother gave her a greeting card that said 'Happy Easter' rather than something like 'Get Well Soon'. Monica took this as another indicator of her grandmother's denial about the cancer risks in the family.

Interestingly, Monica’s father, Mike, feels that their extended family actually does talk about the mutation and cancer risk quite a bit. He also provides a reason for why Monica might be particularly sensitive.

And so um, my wife and I were um supporting my family and they do talk about it, they do discuss it, they're not afraid or ashamed of it, and Monica is saying no. But I think Monica is, she, she's still processing a lot, um, you know she's 28, and, and she's had uh, the bilateral mastectomy and she's not finished with her therapy and um, she has uh, um, she's not happy with the way things are going because she has a lot of pain, and fatigue, she's a little misshapen, and you know, so there's a lot of questions out there. So I think she's a little bit on guard.

Overall, the study data demonstrate that in families in which a BRCA mutation has been identified, there often exist individuals who would prefer to ignore it. These people tend to make their feelings known by avoiding talk about the subject all together. This can create conflict within the families, especially when other family members value open discussions. Again, members of the same family may have different perceptions about how BRCA testing has affected the family dynamics.

\subsubsection{Open communication with family}

As indicated above, many families in the study included at least some members who value open communication about the BRCA mutation. In most families these individuals did find some family members they felt they could be open with. 
Open communication could be detrimental, as evidenced by an exchange between Danielle and one of her sisters, after Danielle tested positive for the mutation and her sister tested negative. Danielle says:

She felt this huge sense of relief and said things in the beginning that were inappropriate and very hurtful, like 'I can look at my daughter in my, her eyes and know she's OK.' You know, things like that, that uh, she didn’t mean.

For the most part, however, open communication was perceived in a positive manner by the participants in the study. For instance, Mary speaks about how happy she is that she can be open with her nuclear family, even when some of their more extended family members are reluctant to talk.

I've, I choose not to let it bother me because I think you know, I'm the only one that really needs to worry about this, and my immediate family is clued in and we talk about it all the time. Everyday we see each other, every time we're on the phone we talk about it. And so um, I mean there's other people that are going to be in denial about some of these issues.

Often, participants whose extended family was resistant to discussion were very open about the topic with their own children. For instance, Danielle realized that being open with her own young daughters about the mutation and about her own prophylactic mastectomy would prepare them to cope with the cancer risk they may face in adulthood.

Danielle: I have two beautiful daughters, 8 and 10. Interviewer: And how are they doing with all of this?

Danielle: Well, they're, it's interesting, you know, [husband] and I have chosen to be, you know, pretty open about this. They don't understand the genetics and that's an OK thing, although, you know we've talked about, they know the words and the gene and that I'm doing this to prevent getting cancer...It's kind of healthy and uh, you know, they see me uh, they see my incisions, they're seeing me you know, as it heals... and uh, in fact on the whole I think it's been really positive and I don't regret how we've dealt with it. They've come on the internet with me when we were looking at [breast] reconstruction and making decisions and decisions like, they're, 'oh look at this one, this one look really good, mom,' and you know, 'dad come see this one,' so I think that's pretty healthy, to deal with it that way. And then like, they may walk this path... and I want them to be uh, you know, whatever they see that you know, if they know this isn't the end of the world, this is one small part in the whole picture... 
Open communication in the family can also occur between only certain members, for instance only between female $B R C A$ mutation carriers, as in the M family. This observation will be discussed thoroughly in section 5.2.3.2.

\subsubsection{No or few perceived changes, or did not mention it}

Although the majority of study participants mentioned that there was some change in the family discussions after BRCA testing, a few participants either did not mention or did not perceive much of a change in the discussions in their families or in fact in the family dynamics at all.

\subsubsection{Theme \# 3: Feeling more or less connected to family members}

The last major theme discussed here is that after BRCA testing in their family, some individuals felt more connected or less connected with certain family members.

\subsubsection{Feeling a special connection with fellow mutation carriers}

Certain study participants expressed that, after receiving their test result, they felt a sense of belonging or a special connection with other family members carrying the mutation. For instance, Mary, who underwent predictive genetic testing in her mid 20s after several aunts, her father and her older sister had tested positive for the family mutation, says:

And so we are, you know, mature and adult, and have been adults through most of the time [her aunts] have been sick, and so again, it's always the topic of discussion and so I feel like an instant sense of belonging and so you know, again because it's not a club I want to belong to but it almost made me feel very welcome, very like, well you know, at least I have this wonderful network. 
In fact, this same participant felt so strongly about the connection with other family members that she actually felt relieved that she tested positive, so that she and her sister could go through the experience together.

This is horrible of course, but I kind of feel like, in a really weird way I felt really, really relieved in a very bizarre way because I had it and my sister did too... We're so close...I almost felt like, 'Well, of course I've got this because she's got this and we do everything together.' And so it was, was easy in a bizarre way to feel, 'Well, I'm not alone and she's not alone and this is just, it's just worked out great.'

Later, she says:

We've got an amazing bond in addition to all the other things, already being sisters and friends, we have this thing that's brought us so much closer...

Another participant, Naomi, who was the first to undergo testing in her extended family, spoke about how testing positive for a mutation made her feel more connected to some of her deceased family members.

My $3^{\text {rd }}$ uncle, Nathan, who was my favorite (and my mom's favorite brother - no coincidence, I'm sure), I believe would've "gotten" it, maybe it even would've helped him (as it has me) make sense of his mother's and sister's deaths. I even think about whether it might have helped his health - perhaps (and this is total conjecture) there was a twinge of pain in his stomach that he ignored, that he wouldn't have if he'd known about the mutation. So in that sense I have a sort of melancholy, belated sense of identifying with him.

Thus, some individuals who discover they have a BRCA mutation can find themselves identifying more or having a special connection with certain family members, either living or deceased.

\subsubsection{Feeling left out if not sharing the family mutation}

This special connection can make others in the family feel isolated or like outcasts in their own families. For instance, in this study relatives who were not at risk of the mutation, like in-laws, as well as the men in the family, who carry a substantially lower cancer risk than 
women, often felt helpless or like an outsider in the family. This was perceived by Elise, a member of the E family, when she said, "I think that my dad feels a little like my brother - left out kind of.” This feeling was especially dramatic in the M family. Here Mike talks about a family gathering in which a 'clique' of female mutation carriers made others feel left out.

And right after that, we went to a family gathering because it was a baptism of my um, one of my youngest nieces, and all the um, BRCA2 uh, victims were in a, club, in a little clique talking. And my wife and my, my, the sister who's never had been tested felt ostracized. And they admitted it, they felt like they were not included in this conversation. They didn't have anything to add, they didn't have anything to uh talk about, they felt they couldn't talk about it so much and they very much felt like they were not in the club. And it was a really strange situation... That um may not be the best news, but to all in the, in the group together and they know certain things and they have certain feelings that nobody else is going to have. Um, I wasn't in that discussion only because they were talking about prophylactic mastectomies, and oophorectomies, and uh, things that weren't going to relate to me so much. Uh and so, but I mean it was like instant cancer club. It was bizarre.

The female family member mentioned here who hadn’t had a cancer diagnosis or genetic testing felt left out since her sisters had all had cancer and were mutation carriers. In fact, one reason she had been reluctant to pursue BRCA testing was because she felt if it was confirmed that she didn't carry the mutation, she would not feel comfortable with her sisters, or her sisters would be angry. Finally, she did pursue testing, with the blessing of her sisters. Members of the M family talk about this family member.

Mary: She said something like you know, 'Sometimes I feel because you know a couple of the other girls have cancer, and I don't, I feel like they have a closer bond than I have with them. And so sometimes I feel left out,' she said, 'like when going through something they call each other and they don't necessarily call me because they don't think I can understand.'

Mike: So after I got my test results she went and did it. Um, partly to, because I think she ostracized that demon, and when admitted that she was afraid that she would be negative, wouldn't feel comfortable being not in the club.

Thus, sharing the mutation and/or sharing the cancer experience associated with it could connect family members but could also isolate others in the family. 


\subsubsection{Feeling isolated or less connected if not receiving wanted family support}

For many testing positive for the mutation, family support played a significant role in whether they felt connected or isolated in their family. Mary seems to have foreseen this when she wanted to test positive so that she could support her sister, Monica, who had already tested positive for the mutation.

Mike: And [Mary] would have felt terrible if she had tested negative because then she couldn't be as uh, as supportive and understanding and sympathetic with her sister.

Danielle provides another example, by describing the isolation and hurt she felt when she did not receive support from her family. Danielle is the only one in her family who tested positive, other than an 80 year old uncle.

Danielle: I didn't expect my friends to understand on the same level. But I did expect my sisters to understand. Either they didn't. Or they weren't able to give me the support I needed. I accept that and I stop looking for it. But the hurt is still there on some level but not to the same intensity. I try to accept them for who they are not what they can give. Truly, I don’t think that they have any idea.

As Danielle articulates, it is hard to tell if this lack of support was because her sisters could not empathize with her since they had not tested positive or because they lacked the skills to support her at all. In fact, sometimes, different coping mechanisms or management decisions were the reason some family members were not as supportive as others wanted. For instance, Claire discusses that even though she and her sister both tested positive for the mutation, she felt less connected to her because her sister did not understand Claire's decision to have a prophylactic mastectomy.

There are two situations where I think family bonds have been affected more strongly. One is, um, with my sister who actually ironically tested positive as well, when she and I made different decisions about mastectomy there was a period of time where I felt a lack of connection. I felt like she tried, was trying to be supportive to me, but honestly she wasn't. She didn't understand why I was doing this, she thought I had gone too far. She grieved the loss of my breasts for me, I think. I mean, I did too, but, um, she thought it was quite draconian. And so we kind of like, we lost touch at some point over this. Um, 
and I think maybe that's kind of getting where we're moving past that now, but there's certainly a period where I felt quite you know, like I wasn't interested in being very close

to her because I didn't feel a sincere support.

Negative reactions of family members, as well as the tendency of certain family members to avoid discussing the topic all together, as outlined previously, can be perceived as a similar lack of support, having the potential to make other family members feel isolated.

Naomi, the participant for whom testing positive made her feel more connected to some of her deceased relatives, also felt less connected to other relatives after testing. She explains that this feeling was based on her prediction that they would have coped with knowledge of the mutation differently from her.

I've never really identified with (or even known) my surviving cousins - going through testing, learning my status, becoming a part of the "world" of people who have a BRCA mutation makes me feel even more separate from them. The two uncles that I never got along with, even though they are dead, I feel sort of similar about - like they would never have "gotten" this, or taken it seriously in any way, and this is just another example of how unlike them I am.

Thus, this study provides several examples of when family coping strategies and support seem to make family members feel more or less connected to their relatives.

\subsubsection{Genetic counseling process as a catalyst for initiating new relationships with} relatives

For one participant, Evelyn, genetic testing served to not only change existing relationships but also served as a reason to kindle new relationships with relatives she never knew. This participant did not know her biological father or any of his relatives before this process. However, through researching her family health history to prepare for genetic counseling, she has met many relatives and has become friends with them, something she feels good about. 
However, the up side is that I met many cousins I never knew about. They all knew about me. Several of us are becoming great friends. We are the same ages, we look alike, we are having fun together. So I have to think that my biological father is smiling down on us.

Thus, this research shows that genetic testing has the potential to make individuals feel closer or more distant from certain relatives. These effects can be due to a special connection felt by sharing the mutation, to the types of coping strategies used in the family and the associated support from family, and to the need to contact long-lost relatives.

\subsubsection{How are these three main themes connected?}

As is likely evident throughout the preceding sections, all three major themes are intricately connected to each other. For instance, disclosing information as part of the role of an index case can incite or influence genetic discussions in the family. In contrast, the types of genetic conversations in the family can impact the burden felt by the index case. As well, the receptivity

of family to discussions can cause individuals, including index cases, to feel more or less connected to each other. Likewise, feeling a connection to or a separation from family after testing can influence the dynamics of relationships, having an effect on family discussions at large. Thus, any change in one domain after genetic testing is likely to influence the others, having potential for dramatic change in family dynamics.

\subsubsection{Changes in family relationships over three years - first and second interviews}

There were very few changes in family relationships noted between the first and second interviews with each participant. Danielle, who did not feel supported by her siblings, noted that 
over the three years or so since the first interview she has come to adjust her expectations of her siblings.

The second part of this for me wasn't feeling left out from friends, but it was a feeling of being left out by my siblings...My sisters and brother really didn’t know how to support me. I was consumed by this in the beginning and they didn't know how, or emotionally could not support me in the way that I needed. That hurt me deeply (and if I let myself, still does). I've had to re-look at my expectations and realize that they could not give me what I needed.

Otherwise, it was hard to tell how family relationships had changed over the years from the first to the second interview. Future studies with the same cohort of participants could involve asking directed questions about their current family relationships, how they compare to what they were like years before, and if any changes were noted, to what do they attribute the change.

\subsubsection{Other themes identified in the analysis}

Other themes were also noted in the analysis but were not expanded upon in this paper. Here they will be listed. Firstly, some participants seemed to be motivated by the memory or legacy of their deceased family members who had cancer. For instance, they often appreciated their own opportunities to have testing for a BRCA mutation and regretted that their deceased relatives did not have the same opportunities. Participants also sometimes expressed a wish to 'pay forward' their own fortune for future generations of their families. Another theme was that parents testing positive for the mutation often expressed guilt for passing on the mutation to their children. Roles of family members other than the index case were also often altered by the news of a BRCA mutation, such as a younger sister doting on her older sister once the older sister tested positive and chose to have a mastectomy. As well, individuals who tested positive for a mutation tended to take their other family member's cancer diagnoses and surgeries more 
personally, since they could very well be their own. Family members also tended to hold back their emotions from others in their family, to protect themselves, to protect their family members, or to protect their family relationships in general. 


\subsection{DISCUSSION}

This study represents one of the few to investigate how testing positive for a BRCA mutation can influence relationships among family members. To summarize the results briefly, some of the families illustrated that family dynamics were altered after testing, and the changes could often be perceived as either positive or negative. Among the many themes identified in the analysis, three in particular were commonly reported and were the focus of this paper: 1 . That the first in the family to have testing or seek genetic counseling takes on a special family role that can be difficult for them; 2. That discussions in the family, especially those associated with BRCA testing, often change after genetic testing; and 3. That individuals may feel more or less connected to certain family members after genetic testing has occurred in the family. The study also demonstrates that these changes in family dynamics can depend on the family history of cancer, prior relationships among the family, emotional coping strategies of relatives, value placed on particular communication patterns, and sharing or not sharing the family's BRCA mutation.

As mentioned earlier, all of these effects of BRCA testing on the family, as well as the determinants of the effects, are related to one another and interconnected. Therefore, we would expect that if BRCA testing impacts one aspect of a relationship between family members, a ripple effect may occur, influencing other aspects in some way. 
Here the study's findings are compared with previous work. Attention is then focused on what health professionals might find useful for their practice based on the findings. Finally, the limitations of the study as well as areas for future research are addressed.

\subsection{STUDY FINDINGS IN THE CONTEXT OF PREVIOUS WORK}

\subsubsection{Theme \# 1: New or changed family roles as the index case}

As outlined in the Background and Significance section, previous studies have shown that individuals often decide to undergo BRCA testing to provide information for their family, some even feeling that their family has a right to know this information (Hallowell, 1999; Tercyak et al., 2007; Phelps et al., 2007; Foster et al., 2004; Daly et al., 2001; Goelen et al., 1999; Foster et al., 2002; Hallowell et al., 2003; Green et al., 1997). Thus, it was not surprising that index cases in the current study tended to feel an obligation or responsibility to inform their relatives of their BRCA mutation. The burden they felt when disclosing the information to their families is also consistent with the findings of previous studies (Kenen et al., 2006; McGivern et al., 2004; d'Agincourt-Canning, 2001; Hallowell et al., 2005b; Costalas et al., 2003). Importantly, the current study demonstrates that the special role of the family's index case can be transferred to others in the family under certain circumstances, as one study participant assumed the obligation and burden of informing relatives of the mutation after her mother, the first in the family to have $B R C A$ testing, passed away from cancer.

For one participant, the new role she assumed as the first in her family to have testing involved acting as a role model for her younger siblings, both in explaining genetic information 
as well as demonstrating how to cope emotionally with cancer and genetic testing. As described, she felt somewhat pressured to fulfill this role. In the literature, there are reports of tested individuals feeling burdened by the need to accurately explain the implications of their test results, especially when they themselves do not fully grasp the concepts (Kenen et al., 2006; DudokdeWit et al., 1997; Costalas et al., 2003). However, to my knowledge, there have been no reports of individuals feeling burdened because they are pressured to model emotional coping for their family in the context of $B R C A$ testing. Importantly, as described above, one reason Elise felt pressured into this role was because, unlike the other index cases in the study, she had no known family history of cancer. Thus, in her case, her new family role was possibly related to the details of her family history.

The new role that index cases tend to take on after testing positive for a BRCA mutation may also be in part due to something special about index cases themselves. One study in particular suggested that index cases think differently than their relatives (Loader et al., 2004). In this study individuals interested in genetic testing (i.e. index cases) had to recruit a family member to also undergo testing. It was found that the index cases tended to perceive their emotional and physical health as worse than did their relatives, even when the index cases were healthy and their relatives had cancer. As well, following genetic counseling and testing, breast cancer worry fell for most recruited relatives but remained steady for most index cases. These trends suggest that those individuals who initiate a genetic consult and testing are more anxious about their health and are more preoccupied by breast cancer worry than are some of their relatives. It is possible then that this psychological profile of typical index cases could at least partially explain the burden they feel after genetic testing. For instance, perhaps their burden derives from predicting that their relatives will feel as anxious and worried as they do with the 
news of the mutation, when in reality this may not actually be true. Future study could further investigate the reasons index cases tend to feel burdened in their new family role.

\subsubsection{Theme \# 2: Genetic testing affects discussions in the family}

As mentioned, several studies have commented on the types of discussions in families after BRCA testing, however few made them a primary focus. The current study reveals that, for some families, genetic testing serves as a catalyst for conversations about cancer or for more general contact. These conversations can improve a relationship if they are welcomed or can upset individuals if they are unwelcome. Similarly, it is common in families for some members to be resistant to discussing cancer or genetic testing, and their reluctance can sometimes isolate or hurt the family members who want to talk about it. Those wanting to talk however do tend to find some relatives to be open with, commonly their children, spouse, or biological relatives with whom they feel a special connection. Open communication can be used to prepare family members like children for the cancer risk they may face in their future.

These results are reminiscent of a study in which Kenen et al. (2004) interviewed unaffected women with a family history of breast and/or ovarian cancer after attending a cancer genetics consult. In contrast to the current study, these women had not had genetic testing, and were not aware of testing results for any of their relatives. Despite this difference, the study by Kenen et al. (2004) identified a very similar range of family communication patterns as did the

current study. This would suggest that learning about the potential for a family BRCA mutation during a genetic counseling session might result in similar types of family communication as actually receiving the news of a BRCA mutation after testing is pursued. Perhaps, in both situations, individuals in the family draw from the family scripts, coping mechanisms and 
heuristics that they have established throughout their lifetimes. Similar forms of communication have also been noted in families in which members are at risk for Huntington disease (HD), an inherited degenerative condition in which movement, cognition and psychiatric state are compromised later in life (Sobel and Cowan, 2003; Holt, 2006; Sobel and Cowan, 2000).

\subsubsection{Theme \# 3: Feeling more or less connected to family members}

Many participants in the current study described that, after genetic testing, they or other relatives felt more or less connected to certain family members. Sometimes a special connection arose from sharing the BRCA mutation with relatives. This has been observed in a study by Duncan et al. (2008) for young people that had genetic testing for HD or familial adenomatous polyposis (FAP), another cancer predisposition syndrome. In the current study, some family members who did not share the mutation felt left out or less connected to their family. To my knowledge, this has not been found previously in BRCA families, however, it has been noted in individuals testing negative for the gene for HD (Sobel and Cowan, 2003; Sobel and Cowan, 2000). Notably, Sobel and Cowan (2003) described one individual who attempted suicide because her negative test result made her feel disconnected from her siblings, who were already displaying the signs of HD.

The current study also establishes that individuals testing positive for a mutation may be at particular risk of feeling isolated in their family if their family members do not share their coping styles. This has been seen several times before in BRCA families (Phelps et al., 2007; Speice et al., 2002) and in families with HD or FAP (Sobel and Cowan, 2000; Sobel and Cowan.,

2003; Duncan et al., 2008). Specifically, the current study highlights that individuals who are the only ones in their family to test positive may be especially at risk of feeling isolated since 
their family may not be able to empathize and provide the support needed. However, the findings also suggest that individuals who share the mutation with close relatives may still feel isolated or disconnected if they cope differently or make different management decisions than these relatives.

Lastly, for one participant, meeting distant relatives while researching her family cancer history was a very positive experience as it allowed her to feel more connected to her family as a whole. However, as Carlsson and Nilbert (2007) point out in their study of families undergoing genetic testing for hereditary non-polyposis colorectal cancer (HNPCC), meeting long-lost relatives may not always be welcomed, and sometimes researching the family cancer history can reveal family secrets like the existence of step/half siblings and extramarital children.

\subsection{IMPLICATIONS FOR GENETICS PROFESSIONALS}

As evidenced by this study, genetic counselors and other genetics professionals might benefit from recognizing that genetic counseling or testing can have profound influences on their patients not only by helping their patients to clarify their risk of cancer but also by influencing their family lives.

Firstly, it could benefit cancer genetics professionals to recognize the special role that index cases can have in their family. This is critical especially since it is not uncommon for patients attending cancer genetics clinics to be the first in their families to pursue counseling and testing (Darcy Thull, personal communication). Professionals can attempt to prepare their patients for this special role or provide anticipatory guidance before receiving their test results. Genetics professionals might also want to consider inquiring about staging or prognosis of sick 
patients since this information could help predict whether the role of index case might shift to another relative, as seen once in this study after the index case passed away from cancer.

Genetics professionals may find it helpful to be aware that women who are the first in their families to have cancer may feel pressured to act as a role model to their families. Unlike those who have a strong family history of cancer, these individuals have not watched older family members be sick or die from cancer, they have not been exposed to stories about cancer in their families, and they have not grown up thinking they were at high risk for cancer. Thus, they have no prior family experiences from which to model their own actions or emotions, and instead take on the responsibility of being a model for the rest of their family. Discovering that they carry a BRCA mutation may intensify this pressure since it implicates that their close family members are very likely to need guidance at some point, after their own cancer diagnoses. Women in this situation are presenting more commonly to genetics clinics for testing, since in recent years it has been recognized that particular family structures, such as having few women in the family, can mask the presence of a BRCA mutation (Weitzel et al., 2007) and thus not everyone who has a BRCA mutation has a dramatic family history of cancer.

Genetics professionals could consider preparing their patients for the types of reactions that their family members might have to testing information. Counselors might review with the patient the relationships he or she has with each relative, as well as the coping skills each relative tends to use, in order to try to identify relationships that may result in conflict or emotional distance after testing. Family or individual therapy may be a useful referral for some of these families.

Importantly, in the families from which more than one member participated in this study, there were several examples of scenarios in which relatives had different perceptions about 
family dynamics. This was true even though the family members asserted that they had a very close relationship with each other. Genetics professionals could draw upon this observation and offer to teach skills to families that would empower them to open up to each other, or they could provide a physical venue for family members to come together and discuss their feelings with one another. Promoting such open communication might prevent feelings of isolation in the family and might make family members aware of the difficult new family roles that some family members assume after testing.

In order to prepare genetics professionals for these types of interventions, training programs should consider how to address such psychosocial concerns. Ideally, both the classroom and the clinical domains of their education programs could include relevant training. Eventually, the efficacy of genetics training and of the counseling interventions outlined above should be assessed in order to determine how well genetics professionals are addressing concerns about BRCA testing and the family.

\subsection{IMPLICATIONS FOR PRIMARY CARE PROVIDERS}

Recent marketing efforts to primary care providers (PCPs) by genetic testing laboratories have placed pressure on PCPs to order BRCA tests and interpret the results. However, there is concern that PCPs in busy practices have neither the time nor the specialized training to address the psychosocial implications of $B R C A$ testing, such as the potential for impact on family dynamics as described in this study. Thus, PCPs might benefit from referring patients considering BRCA testing to genetic counseling services. There, patients can participate in multiple appointments, each up to two hours in length, to discuss with a genetic counselor the potential for testing, a 
service that most PCPs are not in the position to provide. Effort could be directed toward educating PCPs of genetic counseling services and targeting them as a referral agent, underlining the potential for PCPs to save time by referring their patients to genetics.

\subsection{STUDY LIMITATIONS AND FUTURE RESEARCH}

\subsubsection{Recruitment and selection bias}

One limitation to the study was that there may have been bias in the personality traits or the experience of the individuals who participated in the study, due to the nature of participant involvement in the research or to the recruitment method of the initial study. The results of this study suggest that families in which a BRCA mutation is present typically consist of some members who want to talk about the mutation, cancer risk and management, and others who would prefer to avoid these discussions all together. Since this study involved in-depth interviews, it might have attracted the individuals who were more willing to discuss their experience with BRCA testing. Using the FORCE website to recruit for the study may have also selected for individuals who tended to be open or proactive about their cancer risk, since they may have been visiting the site to participate in the online support community or to review the extensive information featured on the site about risk management options. Attempts were made to counter this bias by asking participants if they thought their family members would be interested in participating in the study. However, if family relationships were already strained by $B R C A$ testing, participants might be unwilling to ask their family members to participate. Thus, this bias may be unavoidable in some cases, and participants should be asked to richly describe 
interactions with their family members in order to gain the most accurate information as possible about their relationships with relatives that are unwilling to participate. Future studies involving several members of the same family could be performed in order to better understand the differing viewpoints that seem to be occurring among family members, as described in the Results section.

As well, a limitation of the study was that all participants had tested positive for a BRCA mutation. Further studies should address the experiences of individuals testing negative for a mutation, both in families in which a mutation had been identified as well as in families in which no prior family member had been found to have a mutation. This would be useful in appreciating the full spectrum of experiences that members of tested families can have.

\subsubsection{Grounded theory and interview methodology}

The grounded theory and open-ended interview methodology used in the initial study promoted a rich description of the experience that the participants chose to focus on. However, if family relationships after $B R C A$ testing were not the focus of some participants, very little insight into the dynamics of their families could be gleaned from the secondary analysis. For example, there were a few participants in the study that spoke almost exclusively about their experiences with management choices like surgeries as well as their involvement in community-based organizations. When asked about if or how BRCA testing had influenced their relationships with their families, they would either deny that there was any influence or they would answer with a short statement only. It is hard to discern whether they really did not perceive any change within their families or if they did perceive a change but didn't want to talk about it. In situations where there really were no or only minimal changes in family dynamics, a possible next question would 
be why? Unfortunately, the current study was not able to address this. It would be useful if future studies could try to outline the profile of families whose dynamics are not seriously affected by genetic testing, so that genetics professionals could use this information to identify families at high risk for serious negative changes in family relationships, and try to minimize these upsetting effects.

Another limitation in the interview process was that not all participants were asked in their second interview whether and how their relationships with their families had changed since the first interview. Thus, from the current secondary data analysis, it is hard to describe any trends in how families might incorporate the knowledge of a mutation into the way they interact with each other in the long term. Dr. Hamilton is planning on following the same cohort of participants for several more years. In future interviews with them she could ask them to compare their current family relationships with what they were like years before. The participants could then be asked to comment on any changes they noted. Perhaps questions about the three main themes found in the current study could be used as prompts for the participants to recall how family dynamics may have changed over time. 
APPENDIX A

INSTITUTIONAL REVIEW BOARD APPROVAL LETTER 


\section{University of Pittsburgh}

\section{Institutional Review Board}

3500 Fifth Avenue

Ground Level

Pittsburgh, PA 15213

(412) 383-1480

(412) 383-1508 (fax)

http://www.irb.pitt.edu

\section{Memorandum}

TO:

HEATHER DOUGLAS

FROM:

SUE BEERS, PhD, Vice Chair

DATE:

$12 / 4 / 2007$

IRB\#:

PRO07080253

Secondary Analysis of Qualitative Interviews - The Effect of BRCA Gene Testing on Family

SUBJECT: Relationships.

The above-referenced project has been reviewed by the Institutional Review Board. Based on the information provided, this project meets all the necessary criteria for an exemption, and is hereby designated as "exempt" under section 45 CFR 46.101(b)(4).

Please note the following information:

- If any modifications are made to this project, please contact the IRB Office to ensure it continues to meet the exempt category.

- Upon completion of your project, be sure to finalize the project by submitting a termination request.

Please be advised that your research study may be audited periodically by the University of Pittsburgh Research Conduct and Compliance Office. 


\section{BIBLIOGRAPHY}

Beeson, D. (1997). Nuance, complexity, and context: qualitative methods in genetic counseling research. Journal of Genetic Counseling 6(1):21-43.

Berliner, J.L., \& Fay, A.M. (2007). Risk assessment and genetic counseling for hereditary breast and ovarian cancer: recommendations of the National Society of Genetic Counselors. Journal of Genetic Counseling 16(3):241-260.

Blandy, C., Chabal, F., Stoppa-Lyonnet, D., \& Julian-Reynier, C. (2003). Testing participation in BRCA1/2-positive families: initiator role of index cases. Genetic Testing 7(3):225233.

Boyatzis, R.E. (1998). Transforming qualitative information: Thematic analysis and code development (First ed.). Thousand Oaks, CA: Sage Publications, Inc.

Bradbury, A.R., Dignam, J.J., Ibe, C.N., Auh, S.L., Hlubocky, F.J., Cummings, S.A., White, M., Olopade, O.I., \& Daugherty, C.K. (2007). How often do BRCA mutation carriers tell their young children of the family's risk for cancer? A study of parental disclosure of BRCA mutations to minors and young adults. Journal of Clinical Oncology 25(24):37053711.

Braun, V., \& Clarke, V. (2006). Using thematic analysis in psychology. Qualitative Research in Psychology 3:77-101.

The Breast Cancer Linkage Consortium. (1999). Cancer risks in BRCA2 mutation carriers. Journal of the National Cancer Institute 91(15):1310-1316.

Bredart, A., Autier, P., Audisio, R.A., \& Geragthy, J. (1998). Psycho-social aspects of breast cancer susceptibility testing: a literature review. European Journal of Cancer Care 7:174-180.

Brose, M.S., Rebbeck, T.R., Calzone, K.A., Stopfer, J.E., Nathanson, K.L., \& Weber, B.L. (2002). Cancer risk estimates for BRCA1 mutation carriers identified in a risk evaluation program. Journal of the National Cancer Institute 94:1365-1372.

Carlsson, C., \& Nilber, M. (2007). Living with hereditary non-polyposis colorectal cancer; experiences from and impact of genetic testing. Journal of Genetic Counseling 16(6):811-820. 
Charmaz, K. (2000). Grounded theory: Objectivist and constructivist methods. In N.K. Denzin \& Y.S. Lincoln (Eds.), Handbook of qualitative research (Second ed., pp. 509-535). Thousand Oaks, CA: Sage Publications, Inc.

Charmaz, K. (2006a). Coding in grounded theory practice. In Constructing grounded theory: a practical guide through qualitative analysis (First ed., pp. 42-71). Thousand Oaks, CA: Sage Publications, Inc.

Charmaz, K. (2006b). Memo-writing. In Constructing grounded theory: a practical guide through qualitative analysis (First ed., pp. 72-95). Thousand Oaks, CA: Sage Publications, Inc.

Claes, E., Evers-Kiebooms, G., Boogaerts, A., Decruyenaere, M., Denayer, L. \& Legius, E. (2003). Communication with close and distant relatives in the context of genetic testing for hereditary breast and ovarian cancer in cancer patients. American Journal of Medical Genetics 116A:11-19.

Costalas, J. Wagner, Itzen, M., Malick, J., Babb, J.S., Bove, B., Godwin, A.K. \& Daly, M.B. (2003). Communication of BRCA1 and BRCA2 results to at-risk relatives: a cancer risk assessment program's experience. American Journal of Medical Genetics Part C (Seminars in Medical Genetics) 119C:11-18.

d'Agincourt-Canning, L. (2001). Experiences of genetic risk: disclosure and the gendering of responsibility. Bioethics 15(3):231-247.

d'Agincourt-Canning, L. (2006). A gift or a yoke? Women's and men's responses to genetic risk information from BRCA1 and BRCA2 testing. Clinical Genetics 70:462-472.

Daly, M.B., Barsevick, A., Miller, S.M., Buckman, R., Costalas, J., Montgomery, S., \& Bingler, R. (2001). Communicating genetic test results to the family: a six-step, skills-building strategy. Family and Community Health 24(3):13-26.

Domchek, S.M., Eisen, A., Calzone, K., Stopfer, J., Blackwood, A., \& Weber, B.L. (2003). Application of breast cancer risk prediction models in clinical practice. Journal of Clinical Oncology 21(4):593-601.

DudokdeWit, A.C., Tibben, A., Frets, P.G., Meijers-Heijboer, E.J., Devilee, P., Klijn, J.G.M., Oosterwijk, J.C. \& Niermeijer, M.F. (1997). BRCA1 in the family: a case description of the psychological implications. American Journal of Medical Genetics 71:63-71.

Duncan, R.E., Gillam, L., Savulescu, J., Williamson, R., Rogers, J.G., \& Delatycki, M.B. (2008). "You're one of us now": young people describe their experiences of predictive genetic testing for Huntington disease (HD) and familial adenomatous polyposis (FAP). American Journal of Medical Genetics Part C (Seminars in Medical Genetics) 148C:4755.

Ford, D., Easton, D.F., Bishop, D.T., Narod, S.A., \& Goldgar, D.E. (1994). Risks of cancer in BRCA1-mutation carriers. Breast Cancer Linkage Consortium. Lancet 343:692-5. 
Ford, D., Easton, D.F., Stratton, M., et al. (1998). Genetic heterogeneity and penetrance analysis of the BRCA1 and BRCA2 genes in breast cancer families. American Journal of Human Genetics 62:676-689.

Forrest, K., Simpson, S.A., Wilson, B.J., van Teijlingen, E.R., McKee, L., Haites, N., \& Matthews, E. (2003). To tell or not to tell: barriers and facilitators in family communication about genetic risk. Clinical Genetics 64:317-326.

Foster, C., Watson, M., Moynihan, C., Jones, A., \& Eeles, R. (2002). Genetic testing for breast and ovarian cancer predisposition: cancer burden and responsibility. Journal of Health Psychology 7:469-484.

Foster, C., Evans, D.G.R., Eeles, R., Eccles, D., Ashley, S., Brooks, L., Cole, T., Cook, J., Davidson, R., Gregory, H., Mackay, J., Morrison, P.J., \& Watson, M. (2004). Nonuptake of predictive genetic testing for BRCA1/2 among relatives of known carriers: attributes, cancer worry, and barriers to testing in a multicenter clinical cohort. Genetic Testing 8(1):23-29.

Gilligan, C. (1982). In a Different Voice: Psychological Theory and Women's Development. London: Harvard University Press.

Goelen, G., Rigo, A., Bonduelle, M., \& De Greve, J. (1999). Moral concerns of different types of patients in clinical BRCA1/2 gene mutation testing. Journal of Clinical Oncology 17(5):1595-1600.

Green, J., Richards, M., Murton, F., Statham, H. \& Hallowell, N. (1997). Family communication and genetic counseling: the case of hereditary breast and ovarian cancer. Journal of Genetic Counseling 6(1):45-60.

Hallowell, N. (1999). Doing the right thing: genetic risk and responsibility. Sociology of Health \& Illness 21(5):597-621.

Hallowell, N., Foster, C., Eeles, R., Arden-Jones, A., Murday, V., \& Watson, M. (2003). Balancing autonomy and responsibility: the ethics of generating and disclosing genetic information. Journal of Medical Ethics 29:74-83.

Hallowell, N., Ardern-Jones, A., Eeles, R., Foster, C. \& Lucassen, A. (2005a). Communication about genetic testing in families of male BRCA1/2 carriers and non-carriers: patterns, priorities and problems. Clinical Genetics 67:492-502.

Hallowell, N., Ardern-Jones, A., Eeles, R., Foster, C., Lucassen, A., Moynihan, C. \& Watson, M. (2005b). Men's decision-making about predictive BRCA1/2 testing: the role of family. Journal of Genetic Counseling 14(3):207-17.

Hamilton, R.J., \& Bowers, B.J. (2006). Internet recruitment and e-mail interviews in qualitative studies. Qualitative Health Research 16(6):821-835. 
Hamilton, R.J., Bowers, B.J. \& Williams, J.K. (2005). Disclosing genetic test results to family members. Journal of Nursing Scholarship 37(1):18-24.

Holt, K. (2006). What do we tell the children? Contrasting the disclosure choices of two HD families regarding risk status and predictive genetic testing. Journal of Genetic Counseling 15(4):253-265.

Hughes, C., Lerman, C., Schwartz, M., Peshkin, B.N., Wenzel, L, Narod, S., Corio, C., Tercyak, K.P., Hanna, D., Isaacs, C., \& Main, D. (2002). All in the family: evaluation of the process and content of sisters' communication about BRCA1 and BRCA2 genetic test results. American Journal of Medical Genetics 107:143-150.

Julian-Reynier, C., Eisinger, F., Chabal, F., Lasset, C., Nogues, C., Stoppa-Lyonnet, D., Vennin, P. \& Sobol, H. (2000). Disclosure to the family of breast/ovarian cancer. Genetic test results: patient's willingness and associated factors. American Journal of Medical Genetics 94:13-18.

Kenen, R., Ardern-Jones, A., \& Eeles, R. (2003a). Living with chronic risk: healthy women with a family history of breast/ovarian cancer. Health, Risk \& Society 5(3):315-331.

Kenen, R., Ardern-Jones, A., \& Eeles, R. (2003b). Family stories and the use of heuristics: women from suspected hereditary breast and ovarian cancer (HBOC) families. Sociology of Health \& Illness 25(7):838-865.

Kenen, R., Ardern-Jones, A. \& Eeles, R. (2004). We are talking, but are they listening? Communication patterns in families with a history of breast/ovarian cancer (HBOC). Psycho-Oncology 13:335-345.

Kenen, R., Ardern-Jones, A., Eeles, R. (2006). "Social separation” among women under 40 years of age diagnosed with breast cancer and carrying a BRCA1 or BRCA2 mutation. Journal of Genetic Counseling 15(3):150-162.

Kenen, R.H., Shapiro, P.J., Hantsoo, L., Friedman, S. \& Coyne, J.C. (2007). Women with BRCA1 or BRCA2 mutations renegotiating a post-prophylactic mastectomy identity: selfimage and self-disclosure. Journal of Genetic Counseling 16:789-798.

Loader, S., Shields, C.G., \& Rowley, P.T. (2004). Impact of genetic testing for breast-ovarian cancer susceptibility. Genetic Testing 8(1):1-12.

Lynch, H.T., Lynch, P.M., Albano, W.A., Edney, J., Organ, C.H., \& Lynch, J.F. (1979). Hereditary cancer: ascertainment and management. CA: A Cancer Journal for Clinicians 29(4):216-232.

MacDonald, D.J., Sarna, L., van Servellen, G., Bastani, R., Giger, J.N., \& Weitzel, J.N. (2007). Selection of family members for communication of cancer risk and barriers to this communication before and after genetic cancer risk assessment. Genetics in Medicine $9(5): 275-282$. 
McGivern, G., Everett, J., Yager, G.G., Baumiller, R.C., Hafertepen, A. \& Saal, H.M. (2004). Family communication about positive BRCA1 and BRCA2 genetic test results. Genetics in Medicine 6(6):503-509.

McInerney-Leo, A., Biesecker, B. Bowles, Hadley, D.W., Kase, R.G., Giambarresi, T.R., Johnson, E., Lerman, C. \& Struewing, J.P. (2005) BRCA1/2 testing in hereditary breast and ovarian cancer families II: impact on relationships. American Journal of Medical Genetics 133A:165-169.

NCCN Clinical Practice Guidelines in Oncology - Breast Cancer Screening and Diagnosis Guidelines v.1.2007., - Genetic/Familial High-Risk Assessment: Breast and Ovarian v.1.2007.

Patenaude, A. Farkas, Dorval, M., DiGianni, L.S., Schneider, K.A., Chittenden, A. \& Garber, J.E. (2006). Sharing BRCA1/2 test results with first-degree relatives: factors predicting who women tell. Journal Clinical Oncology 24(4):700-706.

Phelps, C., Wood, F., Bennett, P., Brain, K. \& Gray, J. (2007). Knowledge and expectations of women undergoing cancer genetic risk assessment: a qualitative analysis of free-text questionnaire comments. Journal of Genetic Counseling 16(4):505-14.

Raveis, V.H., \& Pretter, S. (2005). Existential plight of adult daughters following their mother's breast cancer diagnosis. Psycho-Oncology 14:49-60.

Rennie, D.L. (2006). The grounded theory method: application of a variant of its procedure of constant comparative analysis to psychotherapy research. In C.T. Fischer (Ed.), Qualitative research methods for psychologists: introduction to empirical studies (First ed., pp.59-78). San Diego, CA: Elsevier, Inc.

Richards, L., \& Morse, J.M. (2007). Coding. In Readme first for a user's guide to qualitative methods (Second ed., pp.133-151). Thousand Oaks, CA: Sage Publications, Inc.

Smith, K.R., West, J.A., Croyle, R.T., \& Botkin, J.R. (1999). Familial context of genetic testing for cancer susceptibility: moderating effect of siblings' test results on psychological distress one to two weeks after BRCA1 mutation testing. Cancer Epidemiology, Biomarkers \& Prevention 8:385-392.

Sobel, S., \& Cowan, D.B. (2000). Impact of genetic testing for Huntington disease on the family system. American Journal of Medical Genetics 90:49-59.

Sobel, S., \& Cowan, C.B. (2003). Ambiguous loss and disenfranchised grief: the impact of DNA predictive testing on the family as a system. Family Process 42(1):47-57.

Speice, J., McDaniel, S.H., Rowley, P.T., \& Loader, S. (2002). Family issues in a psychoeducation group for women with a BRCA mutation. Clinical Genetics 62:121127. 
Strewing, J.P., Hartge, P., Wacholder, S., Baker, S.M., Berlin, M., McAdams, M., Timmerman, M.M., Brody, L.C., Tucker, M.A. (1997). The risk of cancer associated with specific mutations of BRCA1 and BRCA2 among Ashkenazi Jews. New England Journal of Medicine 336:1401-1408.

Stroup, A.M. \& Smith, K.R. (2007). Familial effects of BRCA1 genetic mutation testing: changes in perceived family functioning. Cancer Epidemiology Biomarkers \& Prevention 16:135-141.

Tercyak, K.P., Peshkin, B.N., DeMarco, T.A., Farkas Patenaude, A., Schneider, K.A., Garber, J.E., Valdimarsdottir, H.B., \& Schwartz, M.D. (2007). Information needs of mothers regarding communicating $B R C A 1 / 2$ cancer genetic test results to their children. Genetic Testing 11(3):249-255.

Thorne, S. (1994). Secondary analysis in qualitative research: issues and implications. In J.M. Morse (Ed.), Critical issues in qualitative research methods (First ed., pp. 263-279). Thousand Oaks, CA: Sage Publications, Inc.

Thull, D.L, \& Vogel, V.G. (2004). Recognition and management of hereditary breast cancer syndromes. The Oncologist 9:13-24.

Tonin, P., Weber, B., Offit, K., et al. (1996). Frequency of recurrent BRCA1 and BRCA2 mutations in Ashkenazi Jewish breast cancer families. Nature Medicine 2:1179-1183.

Weitzel, J.N., Lagos, V.I., Cullinane, C.A., Gambol, P.J., Culver, J.O., Blazer, K.R., Palomares, M.R., Lowstuter, K.J., \& MacDonald, D.J. (2007). Limited family structure and BRCA mutation status in single cases of breast cancer. Journal of the American Medical Association 297(23):2587-2595.

Werner-Lin, A.V. (2007). Danger zones: risk perceptions of young women from families with hereditary breast and ovarian cancer. Family Process 46(3):335-349. 